\title{
A Sensory Neuron Subpopulation with Unique Sequential Survival Dependence on Nerve Growth Factor and Basic Fibroblast Growth Factor during Development
}

\author{
Cristian G. Acosta, ${ }^{1}$ Andrés R. Fábrega, ${ }^{1}$ Daniel H. Mascó, ${ }^{2}$ and Héctor S. López ${ }^{1}$ \\ 1'Instituto de Investigación Médica Mercedes y Martin Ferreyra, INIMEC-Consejo Nacional de Investigaciones Científicas y \\ Técnicas, (5000) Córdoba, Argentina, and ²Cátedra de Biología Celular, Facultad Ciencias Exactas, Físicas y Naturales, \\ Universidad Nacional de Córdoba, (5000) Córdoba, Argentina
}

We characterized a subpopulation of dorsal root ganglion (DRG) sensory neurons that were previously identified as preferential targets of enkephalins. This group, termed P-neurons after their "pear" shape, sequentially required nerve growth factor (NGF) and basic fibroblast growth factor (bFGF) for survival in vitro during different developmental stages. Embryonic P-neurons required NGF, but not bFGF. NGF continued to promote their survival, although less potently, up to postnatal day 2 (P2). Conversely, at P5, they needed bFGF but not NGF, with either factor having similar effects at P2. This trophic switch was unique to that DRG neuronal group. In addition, neither neurotrophin-3 (NT-3) nor brain-derived neurotrophic factor influenced their survival during embryonic and postnatal stages, respectively. The expression of NGF (Trk- $A)$ and bFGF $(\mathrm{flg})$ receptors paralleled the switch in trophic requirement. No single $\mathrm{P}$-neuron appeared to coexpress both $\operatorname{Trk}-A$ and $\mathrm{flg}$. In contrast, all of them coexpressed flg and substance P, providing a specific marker of these cells. Immunosuppression of bFGF in newborn animals greatly reduced their number, suggesting that the factor was required in vivo. bFGF was present in the DRG and spinal cord, as well as in skeletal muscle, the peripheral projection site of P-neurons, as revealed by tracer DilC $_{18} 3$. The lack of requirement of NT-3 for survival and immunoreactivity for the neurofilament of $200 \mathrm{kDa}$ distinguished them from muscle proprioceptors, suggesting that they are likely to be unmyelinated muscle fibers. Collectively, their properties indicate that $\mathrm{P}$-neurons constitute a distinct subpopulation of sensory neurons for which the function may be modulated by enkephalins.

Key words: dorsal root ganglion; NGF; bFGF; switch; survival; trophic dependence; rat; sensory neurons; subpopulation; muscle innervation
Several sensory neuron subpopulations have been identified in the dorsal root ganglia (DRGs) of mammals on the basis of anatomical, electrophysiological, functional, cytochemical, and trophic criteria (Perl, 1992; McMahon et al., 1994; Gilabert and McNaughton, 1997; Baudet et al., 2000). These studies have greatly furthered our understanding of how sensory neurons transmit specific sensory modalities, providing rich insights on central issues such as the transmission of pain (Wood and Docherty, 1997; Caterina and Julius, 1999; Wood and Perl, 1999; Caterina et al., 2000).

We have shown recently that activation of $\delta$-opioid receptors (DORs) inhibited high-voltage-activated $\mathrm{Ca}^{2+}$ currents (HVACCs) in primary rat sensory neurons (Acosta and López, 1999), validating the cellular mechanism that is suspected to mediate the action of enkephalins and exogenous $\delta$-opioid com-

\footnotetext{
Received Jan. 29, 2001; revised July 16, 2001; accepted July 27, 2001.

This work was supported by grants from the International Foundation for Science (F/2632-F2), Fondo Nacional para las Ciencias y la Tecnología (PICT 5-01202), Beca Carillo-Oñativia, and Secretaria de Ciencia y Técnica-Universidad Nacional de Córdoba (UNC) (163/99). H.S.L is a career member of Consejo Nacional de Investigaciones Científicas y Técnicas (CONICET) and professor of the Facultad de Psicología, UNC. C.G.A. is the recipient of a fellowship from CONICET. A.R.F. is a recipient of a fellowship from CONICOR and Agencia Cordoba Ciencia. We thank P. Marchetti for help with the statistical analysis, Dr. A. Lorenzo for helpful comments, Dr. Salvarezza for help with some experiments, and P. Panzetta for the gift of neurofilament antibody.

C.G.A. and A.R.F. contributed equally to this work.

Correspondence should be addressed to Héctor S. López, Instituto de Investigación Médica Mercedes y Martin Ferreyra, Casilla de Correo 389, (5000) Córdoba, Argentina. E-mail: hlopez@immf.uncor.edu.

Copyright (C) 2001 Society for Neuroscience $\quad 0270-6474 / 01 / 218873-13 \$ 15.00 / 0$
}

pounds on the transmission of normal and pain sensation (Dickenson et al., 1987; Standifer et al., 1994). Acosta and López (1999) identified a neuronal subpopulation, referred to as P-neurons after their distinctive "pear-shaped" soma in vitro, in which the frequency of DOR-mediated $\mathrm{Ca}^{2+}$ current inhibition was remarkably high $(75 \%)$ when compared with the other cell types (18-35\%). Those findings suggested that their function could be preferentially modulated by enkephalins and prompted a characterization of the properties of that subpopulation to clearly determine whether they represent a distinct group. P-neurons are of medium size and express substance P (SP), properties that have been useful for classifying primary sensory neurons (Harper and Lawson, 1985; Cardenas et al., 1995; Gilabert and McNaughton, 1997). However, further refinement is needed because several subpopulations share such properties. We hypothesize that P-neurons are likely to constitute a previously uncharacterized group because both their unmistakable shape in vitro and preferential coupling of DOR to their HVACCs have been noted only recently (Acosta and López, 1999).

Taking advantage of their distinct morphology to unequivocally identify P-neurons in culture, this study determined unique characteristics of that cell group concerning trophic requirements during development, anatomical projections, and cytochemical features. Most distinctively, P-neurons sequentially required nerve growth factor (NGF) and basic fibroblast growth factor (bFGF) for survival along embryonic and postnatal stages. The need of specific trophic factors has provided a powerful criterion to define distinct subpopulations of sensory neurons and infer 
their possible physiological role (Levi-Montalcini and Angeletti, 1968; Kucera et al., 1995; Lewin and Barde, 1996; Davies, 1997). In particular, the switch of neurotrophic requirements has been recognized recently, underscoring a developmental complexity that goes beyond the classical view of target-derived trophic support (Birren et al., 1993; Molliver and Snider, 1997; Enokido et al., 1999; Baudet et al., 2000; Enomoto et al., 2000). P-neurons also displayed a recognizable cytochemical pattern and supplied sensory innervation to skeletal muscle. These data strongly indicate that they constitute a subpopulation of sensory neurons with distinctive developmental and cellular characteristics, in addition to the previously reported high sensitivity to enkephalins (Acosta and López, 1999).

\section{MATERIALS AND METHODS}

Cell culture. All procedures were in accordance with the Guide for the Care and Use of Laboratory Animals of the Society for Neuroscience. Sensory neurons from DRGs of rat embryos or newborn rats (up to $7 \mathrm{~d}$ old) were isolated as described previously (Acosta and López, 1999). Briefly, embryonic or postnatal DRGs were enzymatically dissociated by incubating the tissue for $15-30 \mathrm{~min}$ at $37^{\circ} \mathrm{C}$ with $0.125 \%$ trypsin and $0.625 \%$ collagenase, or $0.25 \%$ trypsin and $1.25 \%$ collagenase, respectively. The enzymatic activity was halted by adding $1 \mathrm{ml}$ of Eagle minimal essential medium supplemented with $10 \%$ fetal bovine serum (MEM10). After centrif ugation at $2000 \mathrm{rpm}$ for $5 \mathrm{~min}$, the pellet was resuspended in MEM10 containing different trophic factors or the compound K252a at the concentrations specified in Results. A final step of cell dissociation was performed mechanically by passing the material through Pasteur pipettes of increasingly smaller tip diameters. Approximately $70 \mu 1$ of the cell suspension were plated on coverslips coated with $0.25 \%$ collagen and $0.05 \%$ poly-D-lysine. Embryonic day 18 (E18) cultures were grown on poly-D-lysine $1 \mathrm{mg} / \mathrm{ml}$ alone $\left(\sim 300 \mathrm{ng} / \mathrm{mm}^{2}\right)$ because the neurons showed some tendency to detach from the mixed substrate. No differences were found in the survival of postnatal neurons grown in any of those substrates. Plating cell density was standardized, using a Neubauer chamber, to $\sim 10^{4}$ cells per milliliter. The coverslips were placed in an incubator $\left(36^{\circ} \mathrm{C}, 5 \% \mathrm{CO}_{2}\right)$ for $1-2 \mathrm{hr}$ to allow for cell adhesion. Then, MEM10 alone or supplemented with trophic factors or K252a was added to the culture dishes containing the coverslips until reaching a volume of $\sim 2 \mathrm{ml}$. The cultures were kept in those conditions for $24 \mathrm{hr}$ to permit the stabilization of neuronal number and morphological phenotypes. Then, we performed the first neuronal counting, which was defined as the initial condition in all survival assays. Immediately after the first counting, the MEM10 was completely replaced by defined media N2 alone (control groups) or supplemented with trophic factors or K252a. Half of the media was replaced every $48 \mathrm{hr}$ thereafter, but a fresh aliquot of trophic factors or K252a was added daily to the media.

The cultures consisted of a mixed population of neuronal and nonneuronal cells. Two consecutive applications of 5-10 $\mu \mathrm{M} \beta$-arabinocytofuranoside (at days 2 and 3 ) were used to eliminate dividing fibroblasts. In some cultures the dissociated ganglia were passed throughout a $20 \%$ Percoll gradient by centrifugation at $2500 \mathrm{rpm}$ for $6-8 \mathrm{~min}$ to reduce the fibroblast population. Penicillin-streptomycin (150 U/150 $\mu \mathrm{g}$ per milliliter, respectively) was always included in the media. The following definitions were used in this study: E0 was defined as the day of mating, embryonic age was defined relative to $\mathrm{E} 0$, postnatal day $0(\mathrm{P} 0)$ was the day of birth, and postnatal age was defined with respect to P0.

Evaluation of neuronal survival. Neuronal survival was assessed in cultures grown on etched grid coverslips from Bellco Glass (Vineland, $\mathrm{NJ}$ ); alphanumeric coordinates on the coverslips allowed counting the cells within an identified region of the culture. A minimum of 500 neurons were counted in each replication of the experiments. Taking advantage of their relatively small fractional contribution to the culture population, the survival of each individual P-neuron was followed and recorded. Survival was estimated as the average percentage ( \pm SEM) of cells remaining alive relative to their number at the initial condition. The neurons were counted daily until no P-neurons remained in the culture. The culture density at the time of the first neuronal counting, estimated using the coverslip etched grid, already reflected the survival-promoting effect of the different factors at embryonic or postnatal stages. The survival of P-neurons showed no correlation with the observed density. For example, similar survival rates after $90 \mathrm{hr}$ in vitro were obtained with
bFGF, despite a threefold difference in density after the first $24 \mathrm{hr}$ in culture. Dying cells were recognized on the basis of signs such as pyknosis, shrinkage and fragmentation, membrane disruption, loss of adhesion to the substratum or complete lysis. Because, as noted above, the morphological integrity of each individual P-neuron was recorded, the chances of mistakenly counting a live cell as dead, or vice versa, were negligible. P-neurons never became round over the entire duration of the experiment. Very few neurons identified as round at the time of the first counting became pear-shaped by the time of the second counting (48 $\mathrm{hr}$ after plating), keeping that phenotype thereafter, a change that was unrelated to the presence of any of the trophic factors. Those cells were counted as P-neurons and might have caused, at the most, an overestimation of survival of $10 \%$. The number of replications of the experiments is stated in Results or Figure legends.

The results were analyzed statistically using a two-way ANOVA test [treatment $\times$ days in vitro (DIV)]. The percentage of P-neuron survival was the dependent variable, and the repeated measures were provided by the survival percentage at each consecutive DIV. The interaction between factors was evaluated with multiple comparison tests (post hoc analysis with the Tukey test; $p=0.05)$. For E18, P2, and P5, the interaction values were $F_{(6,18)}=12.63, p<0.0001 ; F_{(6,18)}=12.97, p<$ 0.0001 ; and $F_{(8,24)}=5.69, p<0.0001$, respectively.

Immunocytochemistry. The cells were withdrawn from the incubator 24 hr after plating and washed for 5 min with PBS, then fixed with $4 \%$ paraformaldehyde-sucrose for $20 \mathrm{~min}$ at $37^{\circ} \mathrm{C}$ and washed again for 5 min with PBS. In experiments detecting endogenous proteins (bFGF, substance $\mathrm{P}$, neurofilament $200 \mathrm{kDa}, \beta$-tubulin isoform III), the cells were permeabilized with $0.2 \%$ Triton $\mathrm{X}-100$ for $5 \mathrm{~min}$, and nonspecific binding sites were blocked with 5\% bovine serum albumin (BSA) for 1 $\mathrm{hr}$. Surface antigen detection ( $T r k-A$ and $f l g$ ) did not use permeabilization. The coverslips were covered with primary antibodies, usually overnight at $4^{\circ} \mathrm{C}$, in $1 \%$ BSA at the dilutions indicated in Results. The primary antibodies were subsequently washed three times with PBS, and the cells were incubated at room temperature for $1 \mathrm{hr}$ with the corresponding secondary antibodies, labeled with fluorescein isothyocianate (FiTC) or rhodamine. Finally, the cells were washed three times, and the coverslips were mounted on glasses with FluorSave (Calbiochem, La Jolla, CA). In double-staining experiments, the described procedure was repeated after the incubation with the second primary antibody. Images were acquired using an epifluorescence microscope (Axiovert TM-31; Zeiss, Oberkochen, Germany) and recorded on optical disk.

A series of preliminary experiments established the appropriate dilutions of primary antibodies as those allowing a clear distinction from the background and causing no labeling of cell types (neurons or other) that were known to be negative for the tested antigen. The antibodies against $\operatorname{Trk}-A(\alpha-\operatorname{Trk}-A), f g(\alpha-f l)$, and bFGF $(\alpha-b F G F)$ were tested with Western immunoblots following standard protocols (Cáceres et al., 1992) and found to specifically label the bands corresponding to the molecular weight of their target proteins (see Figs. 5, bottom panel, 6B, 9A). The proteins for Western blotting were obtained from tissues of E20, P1, or $\mathrm{P} 5$ rats (as indicated in the corresponding figure legends), homogenized at $4^{\circ} \mathrm{C}$ in Ripa $1 \times$. Samples were centrifuged at $14,000 \mathrm{rpm}$ for $15 \mathrm{~min}$; the supernatant was recovered, centrifuged again, and kept at $-20^{\circ} \mathrm{C}$. The proteins were quantified using colorimetric methods. In all cases, 20 $\mu \mathrm{g}$ of proteins were seeded in each lane. Although a 1:200 dilution of $\alpha$-Trk- $A$ labeled a single band corresponding to Trk- $A(\sim 135 \mathrm{kDa})$, it only moderately labeled cultured embryonic neurons at a 1:20 dilution, a result attributed to disruption of the trypsin-sensitive extracellular loop of $\operatorname{Tr} k-A$ recognized by the antibody after the enzymatic treatment required for the DRG dissociation. We used $\alpha$-Trk- $A$ at a 1:50 dilution because it yielded the same number of labeled neurons as lower dilutions, with a minor loss of fluorescence intensity. The $\alpha$-flg produced satisfactory labeling in the range 1:400-1:1000.

Identification of targets innervated by P-neurons. To determine the peripheral tissue innervated by P-neurons, we injected several possible targets with the lipophilic fluorescent neuronal tracer $\mathrm{DiIC}_{18}(3)$ (DiI). A single peripheral site was injected per animal. After being selectively taken up by neuronal termini present in the region of application, this compound diffuses along the cell membrane without crossing to other neurons (Honig and Hume, 1989). Its detection in cultured P-neurons was used to qualitatively specify their peripheral target. To this end, the DRGs were dissected and cultured on poly-D-lysine-covered glass in low-volume videomicroscopy chambers $3 \mathrm{~d}$ after the injections, a time at which the dye presumably reached the somata of sensory neurons according to its diffusion rate on lipid membranes in vivo $(6-7 \mathrm{~mm} / \mathrm{d})$. A 
very small volume of DiI at low concentration $(2-5 \mu \mathrm{l}$ of $1 \% \mathrm{DiI}$ in $N, N$-dimethylformamide) was injected into skin, subcutaneous tissue, skeletal muscle, or joints with a Gilmont microsyringe. This protocol minimized the possibility of dye diffusion to neighboring tissues, so that the chances of assigning labeled P-neurons to a wrong target were negligible. Because this injection protocol might miss a sparse cutaneous innervation by P-neurons, we also evaluated this possibility by injecting several subcutaneous sites of a rat with larger volumes of DiI at high concentration (six injections of $10 \mu \mathrm{l}$ each, $3 \%$ DiI).

Treatment with antibody against $b F G F$ in vivo. For $3 \mathrm{~d}$, rats of age P2 received daily injections of $100 \mu \mathrm{l}$ of $\alpha-b F G F$ diluted 1:10 in PBS. The control group was injected similarly with PBS alone. At P6, DRG sensory neurons from test and control groups were isolated, and all neurons present in the culture were counted $24 \mathrm{hr}$ after plating to evaluate the number of P-neurons in treated animals and controls. The serum of PBSor antibody-injected animals was examined with the technique of dot immunoblots to assess whether $\alpha-b F G F$ reached the bloodstream after its intraperitoneal injection. The serum was obtained 1 or $12 \mathrm{hr}$ after an injection of PBS or antibody. To separate the serum, the blood from injected animals was collected in heparinized Eppendorf tubes (50 $\mathrm{U} / \mathrm{ml}$ ), incubated for $1 \mathrm{hr}$ at $37^{\circ} \mathrm{C}$, and kept overnight at $4^{\circ} \mathrm{C}$. Then, samples were centrifuged at $10,000 \mathrm{rpm}$ for $10 \mathrm{~min}$ at $4^{\circ} \mathrm{C}$, and the supernatant was collected and centrifuged again. The new supernatant (serum, $\sim 100 \mu \mathrm{l}$ ) was kept at $-20^{\circ} \mathrm{C}$ until used. To detect the $\alpha-b F G F, 10$ $\mu \mathrm{l}$ dots containing $250 \mathrm{ng}$ of pure human bFGF were added to a nitrocellulose membrane, dried, and allowed to bind to the paper for $1 \mathrm{hr}$. This resulted in a final concentration of bFGF of $\sim 25 \mu \mathrm{g} / \mathrm{ml}$, considered optimal for this technique. Then, the nitrocellulose membranes were washed three times with TBS for 5 min and blocked overnight at $4{ }^{\circ} \mathrm{C}$ with a 5\% milk suspension in TBS plus $0.05 \%$ Tween 20 (TBST). On the following day, the membranes were incubated for $18 \mathrm{hr}$ at $4^{\circ} \mathrm{C}$ with the sera or with $\alpha-b F G F$ diluted in TBST. Finally, the membranes were washed several times with TBST and incubated with a biotinylated mouse anti-rabbit IgG (1:400) for $1 \mathrm{hr}$ at room temperature, which would then conjugate the rabbit $\alpha-b F G F$ present in the serum of injected animals. After three washouts with TBST, the membranes were exposed to a peroxidase-extravidin complex (1:2000) for $30 \mathrm{~min}$ at room temperature. The Enhanced Chemiluminescence reaction kit was used to detect the antibody. Exposure time was 20-30 sec.

Electrophysiology. $\mathrm{Na}^{+}, \mathrm{K}^{+}$, and $\mathrm{Ba}^{2+}$ currents were recorded using the whole-cell configuration of the patch-clamp technique (Hamill et al., 1981). Appropriate external and pipette solutions for each current type were used as described elsewhere (Acosta and López, 1999; Everill and Kocsis, 1999).

Antibodies and reagents. The neuronal tracer $\operatorname{DiIC}_{18}(3)$ was obtained from Molecular Probes (Eugene, OR). Rat tail collagen type I was from Biomedical Technologies (Stoughton, MA), and the enzymes used for tissue dissociation were from Worthington (Lakewood, NJ). All trophic factors and K252a were from Alomone Labs (Jerusalem, Israel). The rabbit $(\mathrm{Rb})$ polyclonal anti-human bFGF (affinity purified, raised in rabbit against a peptide corresponding to amino acids 3-17 mapping within the $\mathrm{N}$-terminal region of human $\mathrm{bFGF}$ precursor), $\mathrm{Rb}$ polyclonal anti-rat FGF receptor 1 (affinity purified, raised in rabbit against a peptide corresponding to amino acids 808-822 mapping within the C-terminal region of human FGFR-1), and mouse monoclonal anti-TrkA (clone 6G10) were from Research Diagnostics (Flanders, NJ). The monoclonal anti-bovine bFGF antibody was from Chemicon (Temecula, $\mathrm{CA}$ ). The antibody against substance $\mathrm{P}$ was from Sera-Lab (commercialized by Accurate Chemical \& Scientific Corp.,Westbury, NY). The monoclonal mouse anti- $\beta$ tubulin isotype III (clone SDL.3D10), polyclonal $\mathrm{Rb}$ anti-neurofilament 200 , and all other reagents were obtained from Sigma (St. Louis, MO). Stock solutions of trophic factors were prepared in sterile water; aliquots were maintained at $-70^{\circ} \mathrm{C}$ for no more than 3 months. Stock solution of K252a was prepared in cell culturetested DMSO to yield a 1:2000 dilution of the organic solvent in the culture medium. No adverse effects on neurons have been reported for this concentration of DMSO. The photosensitive K252a was stored in a light-proof container at $-20^{\circ} \mathrm{C}$ until used, and the dishes treated with this compound were protected from light.

\section{RESULTS}

\section{Subpopulation of P-neurons in culture}

The distinct pear-shaped soma of the sensory neurons, which for that reason we have designated P-neurons, allowed different in-
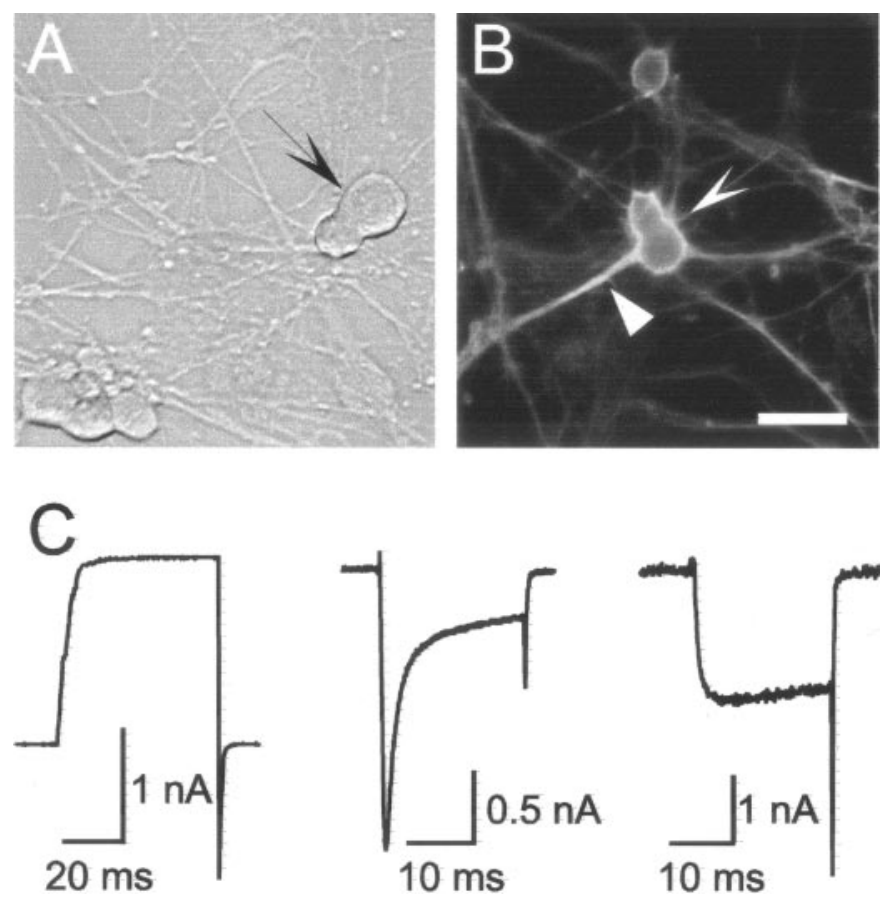

Figure 1. Morphological phenotype and ion currents of "pear"-shaped sensory neurons (P-neurons) in culture. $A$, Typical P-neuron (arrow) in a DRG culture from a rat embryo (E18). Phase contrast photograph after 8 DIV. For comparison, round sensory neurons were included in the view field (bottom left). B, Labeling of the soma (sharp arrowhead) and axon (triangle arrowhead) of a P-neuron with an antibody against the class III isoform of $\beta$-tubulin. Culture from a rat of age P5 after 2 DIV, supplemented with bFGF (10 ng/ml). Scale bar indicates $20 \mu \mathrm{m}$ in $A$ and $30 \mu \mathrm{m}$ in $B$. $C$, Expression of voltage-activated ion currents in three different postnatal P-neurons. The left, middle, and right panels show whole cell currents through $\mathrm{K}^{+}, \mathrm{Ca}^{2+}$ plus $\mathrm{Na}^{+}$, and $\mathrm{Ca}^{2+}$ channels, respectively, recorded under voltage clamp. The permeant ions were $\mathrm{K}^{+}, \mathrm{Ca}^{2+}$ plus $\mathrm{Na}^{+}$, and $\mathrm{Ba}^{2+}$, and the current was activated with voltage pulses to $0-10$ $\mathrm{mV}$ from holding potentials of -70 or $-80 \mathrm{mV}$.

dependent observers to readily and consistently identify them in DRG primary cultures (Fig. $1 A$ ). The other subpopulations were classified according to the diameter of their round somata into small $(<15 \mu \mathrm{m})$, medium $(15-26 \mu \mathrm{m})$, and large $(>26 \mu \mathrm{m})$ neurons (Perl, 1992; Gilabert and McNaughton, 1997). By size, $\mathrm{P}$-neurons corresponded to the medium size group. Inspection of a large number of cultures established from rats of increasing ages (E18-P9), at $1 \mathrm{~d}$ intervals, showed that they contributed $4-7 \%$ of the total population in vitro throughout that period, with the larger percentages at postnatal stages. They might represent a subset of a larger subpopulation, of which only a fraction assumes a pear-shaped soma. It was this feature, however, that allowed their unequivocal identification as a separate group. They exhibited characteristics of healthy neurons such as the development of axons after several days in vitro, as shown by labeling the axonal protein class-III $\beta$-tubulin (Fig. 1B) (Ferreira and Caceres, 1992), and a normal expression of currents through several voltagedependent ion channels $\left(\mathrm{Na}^{+}, \mathrm{K}^{+}\right.$, and $\mathrm{Ca}^{2+}$ ) (Fig. 1C). $\mathrm{P}$-neurons were present already from the moment of cell plating, as well as in cultures grown on different substrates such as laminin (10 $\mu \mathrm{g} / \mathrm{ml})$, fibronectin $(15 \mu \mathrm{g} / \mathrm{ml})$, and collagen $\left(1 \mu \mathrm{g} / \mathrm{mm}^{2}\right)$ (data not shown). Thus, their peculiar shape, which exhibited little change in long-term cultures (up to $14 \mathrm{~d}$ ), did not appear to reflect either cell injury or abnormal cell function. 
Figure 2. Time course of the survival of P-neurons in cultures supplemented with NGF or bFGF from animals of different ages. $A$, Average percentage $( \pm \mathrm{SEM})$ of surviving $\mathrm{P}$-neurons as a function of DIV, relative to their number at 1 DIV (taken as $100 \%$ ), in cultures established from rats of ages E18, P2, and P5. The cultures were maintained in defined media alone (squares) or defined media supplemented with $50 \mathrm{ng} / \mathrm{ml}$ NGF (white circles) or $10 \mathrm{ng} / \mathrm{ml}$ bFGF (black circles). Each plot contains data from three experiments. NGF but not bFGF promoted the survival of E18 neurons (left panel). The reversed result was obtained with P5 neurons (right panel). At P2 (middle panel), the factors had similar effects. Analysis of the data at 2-5 DIV (ANOVA, and Tukey post hoc test; $p=$ 0.05 ) indicated highly significant statistical differences (asterisks) between the NGF treatment and bFGF treatment or control (E18), between NGF or bFGF treatment and control (P2), and between bFGF treatment and NGF or control (P5). B, Dose-response curve of the average survival $( \pm \mathrm{SD})$ of P-neurons from P5 animals (estimated at 3 DIV) as a function of bFGF concentration $(n=2)$. $C$, The survival-promoting effect of NGF $(50 \mathrm{ng} / \mathrm{ml})$ on E20 P-neurons was completely blocked by $\operatorname{Trk}$ - $A$ kinase activity inhibitor K252a (50 nM) $(n=2)$. The bars indicate the percentage of survival $( \pm \mathrm{SD})$ after 4 DIV in defined media alone $(C)$ or supplemented with NGF $(N)$, K252a $(K)$, or both $(N+K)$ at the concentrations specified above. K252a prevents the effect of NGF in a statistically significant way (see asterisk).
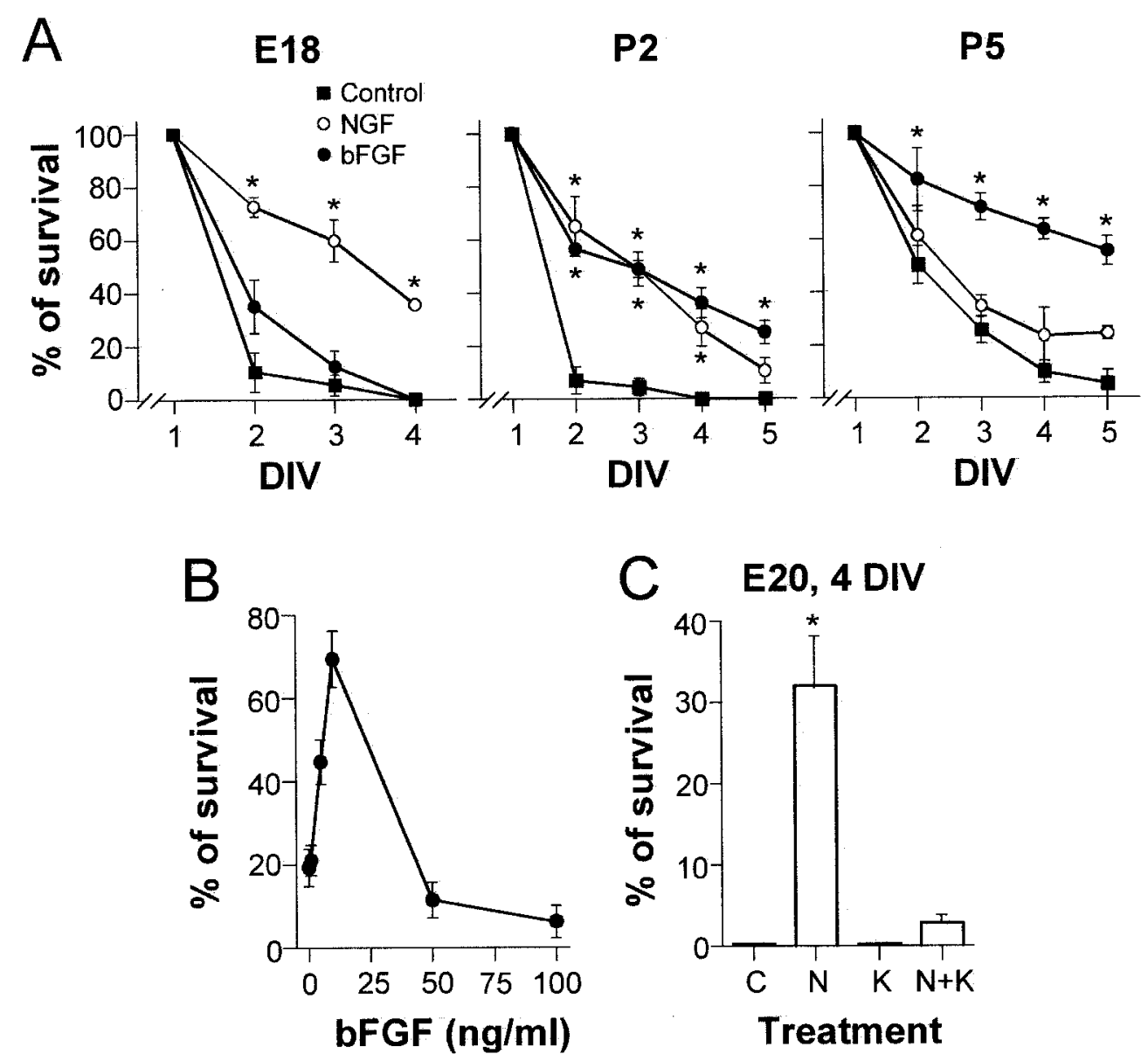

\section{Requirement of NGF and bFGF for the survival of P- neurons during development}

Distinct subpopulations of sensory neurons require for survival during development one or more specific trophic factors (LeviMontalcini and Angeletti, 1968; Ruit et al., 1992; Kucera et al., 1995; Lewin and Barde, 1996; Davies, 1997). To characterize the properties of P-neurons, we examined whether they depended on specific trophic factors during embryonic and early postnatal development by evaluating their survival in cultures established from animals of increasing ages (E18-P5), supplemented with NGF, bFGF, neurotrophin-3 (NT-3), or brain-derived neurotrophic factor (BDNF). The results were compared with the survival rates of round neurons in the same cultures.

The survival of P-neurons depended on NGF and bFGF, but not on NT-3 or BDNF. The plots of Figure $2 A$ illustrate the survival of P-neurons over 4-5 DIV in defined media alone (control), or supplemented with NGF or bFGF. The requirement of NGF and bFGF occurred in a sequential fashion during development. At E18, NGF (50 ng/ml) promoted the survival of $35.6 \pm 0.5 \%$ of P-neurons at 4 DIV (Fig. $2 A$, left), whereas none survived in defined media alone or with bFGF $(10 \mathrm{ng} / \mathrm{ml})$. The difference between the survival observed with NGF and any of the other treatments (control or bFGF) was statistically significant over the entire period assayed (2-4 DIV). Conversely, at P5 $63.5 \pm 3.9$ and $55.3 \pm 5.3 \%$ of P-neurons survived with bFGF at 4 and 5 DIV, respectively, whereas the effect of NGF was barely above control (Fig. $2 A$, right). The effect of bFGF was statistically significant with respect to both $\mathrm{NGF}$ and control. NGF and bFGF had similar effects at P2 (Fig. $2 A$, middle), with $\sim 50 \%$ of $\mathrm{P}$-neurons surviving after $3 \mathrm{DIV}$ in the presence of either factor alone, an effect that differed statistically from the virtual lack of survival observed in control conditions. At P3, bFGF promoted considerably more survival than NGF $(44.2 \pm 8.2$ and $15.8 \pm$ $2.2 \%$, respectively, at $3 \mathrm{DIV})$. The modest survival that was observed with nonsupplemented media after 3 DIV at P5 (25.5 \pm $5.1 \%$ ) most likely reflected the progressive drop in trophic factor requirements of sensory neurons after birth (Levi-Montalcini and Angeletti, 1968). The unmistakable morphology of P-neurons, together with the alphanumeric-coded grid of the coverslips onto which the cells were plated, allowed us to individually follow each P-neuron over several DIV, assuring that the observations corresponded to that single subpopulation of sensory neurons.

The concentrations of NGF and bFGF used in these experiments were those that optimally promote survival as shown elsewhere for NGF (Ruit et al., 1992) and here for bFGF (Fig. $2 B$ ). In agreement with other reports in neurons, 5-10 $\mathrm{ng} / \mathrm{ml}$ bFGF was the most effective concentration, with smaller and larger concentrations being ineffective and detrimental, respectively (Schmidt and Kater, 1993; Abe and Saito, 2000). The alkaloid K252a (50 nM), an inhibitor of the tyrosine kinase pathway that is activated by the high-affinity receptor of NGF (Trk-A) (Koizumi et al., 1988), prevented the effect of that neurotrophin on the survival of E20 P-neurons (Fig. 2C). Dose-response data showed that $50 \mathrm{~nm} \mathrm{K252a}$ inhibits $80 \%$ of $\operatorname{Tr} k-A$ kinase activity, 

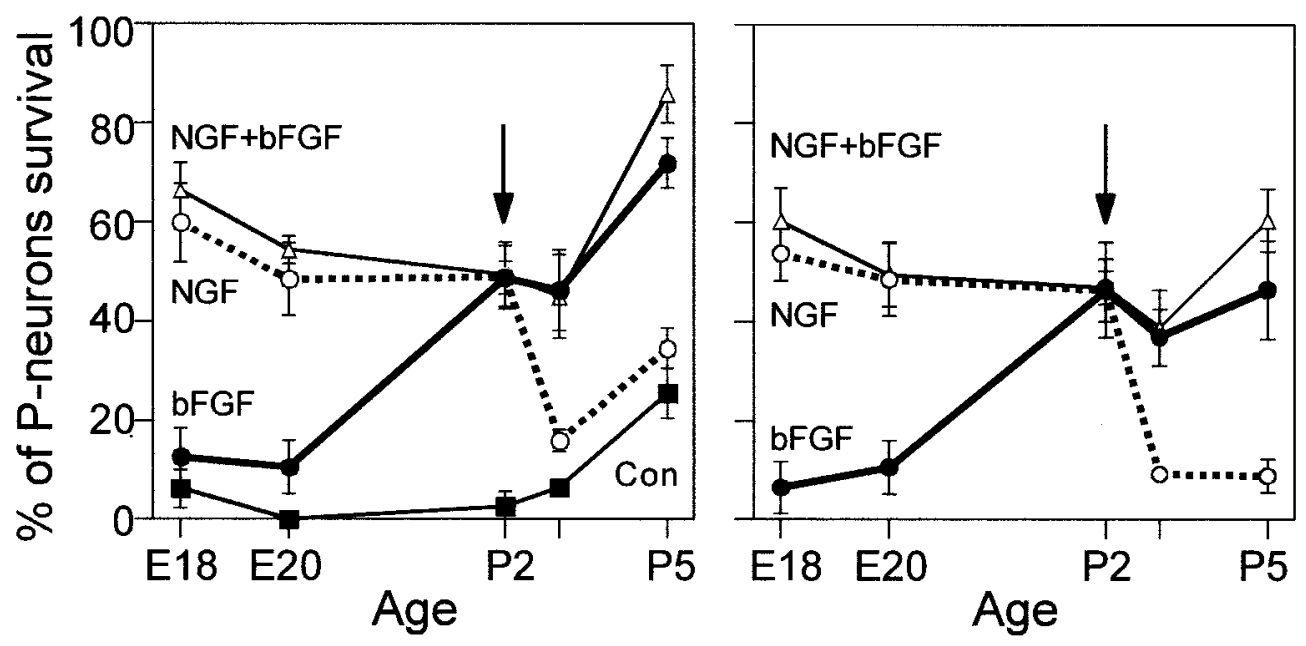

Figure 3. Switch in the requirement of P-neurons from NGF to bFGF at different developmental stages. Left, average percentage $( \pm$ SEM $)$ of survival of P-neurons after 3 DIV, relative to their initial number, in cultures established from animals of different embryonic and postnatal ages, maintained in defined media alone (control, squares), supplemented with NGF $(50 \mathrm{ng} / \mathrm{ml}$; white circles $)$, bFGF (10 ng/ml; black circles), or both NGF + bFGF (50 and $10 \mathrm{ng} / \mathrm{ml}$, respectively; triangles). Right, same data as in left, but subtracting in each experiment the percentage of survival in control conditions (defined media alone) to make the trophic switch clearer. The switch of trophic dependence occurred at P2, defined as the day at which NGF and bFGF had similar effects (arrow). The survival obtained with both factors was not larger than that observed with the most effective factor at a given age, although it appeared to approach the sum of NGF and bFGF effects at E18 and P5. The survival-promoting effects of the trophic factors were statistically significant, as indicated in Figure 2. For better visualization of the trophic switch, statistically significant differences were not labeled with asterisks in these summary plots.

fully blocks the Trk- $A$-mediated differentiation of PC12 cells, and has negligible effects on other tyrosine kinase receptors (Berg et al., 1992). Our results are thus consistent with NGF acting through the signaling pathway involving Trk- $A$ and tyrosine kinase activity, and not through its low-affinity receptor p75 (Lewin and Barde, 1996) or other tyrosine kinase pathways. The effect of NGF most likely reflected its well known ability to prevent embryonic sensory neurons from entering programmed cell death (Vogel, 1993; Yao and Cooper, 1995). Postnatal P-neurons deprived of bFGF underwent nuclear changes typically associated with apoptosis (data not shown).

Figure 3 (left) summarizes all of our data on the extent and time course of the dependence of P-neurons on NGF and bFGF as a function of the age of the animal at the time of the isolation of sensory neurons (E18-P5). The data points indicate the average percentage $( \pm \mathrm{SEM})$ of surviving neurons after $3 \mathrm{DIV}$ in control media alone or supplemented with NGF alone, bFGF alone, or both factors. Both factors together promoted a survival rate similar to that achieved individually by the most effective factor at any given age. The switchover of survival dependence, defined as the day at which the survival-promoting effects of NGF and bFGF were similar, occurred at P2. The gradual increase in survival rate over P3-P5 with any factor alone or combined was similar to that observed in control cultures (Fig. 3, left) and was assumed to reflect the decrease in trophic factor requirements after birth. To show more clearly the switch in trophic factor requirement, the background survival that was obtained in the absence of factors was subtracted as follows. In each experiment, the control values (no treatment) were subtracted from the treatment values. Then, the data were averaged (Fig. 3, right).

\section{The sequential requirement of NGF and bFGF was unique to $\mathbf{P}$-neurons}

Only P-neurons required NGF prenatally and bFGF postnatally. None of the other sensory subpopulations (round small, medium, and large) depended on those factors in a sequential fashion. However, NGF or bFGF did affect the survival of embryonic or postnatal round sensory neurons in the way illustrated in Figure $4 A$. We focused on the survival of round neurons in cultures that were obtained from E18 and P5 animals because the switch in trophic dependence of P-neurons was most obvious at those ages.
Classifying E18 round neurons into small, medium, and large groups was uncertain because their size in culture changed considerably with trophic factors at that early stage, and the size differences in the first two groups were subtle. Therefore, E18 round neurons were lumped together into a single class ("round"). P5 round neurons were readily sorted into small, medium, and large categories. As expected from the literature (Silos-Santiago et al., 1995), NGF greatly enhanced, in a statistically significant manner, the survival of round E18 neurons $(70.1 \pm 14.5 \%$ at 3 DIV) when compared with control cultures $(14.3 \pm 8.3 \%$ at $3 \mathrm{DIV}$ ) (Fig. $4 A$, left). In contrast to its lack of effect on postnatal P-neurons, NGF also enhanced the survival of P5 round neurons, with equal effectiveness among categories (between 76 and $84 \%$ at 3 DIV), although the increase in survival over the control was smaller because of the expected drop in the requirement of trophic factors of postnatal sensory neurons (Fig. $4 A$, right) (see Ehrhard and Otten, 1994; Wewetzer et al., 1999). bFGF promoted the survival of E18 round neurons but had no effect on the survival of small, medium, or large P5 round neurons, as illustrated in Figure $4 A$. In the presence of bFGF, $30.2 \pm$ $9.7 \%$ of embryonic round neurons survived after 3 DIV, compared with $14.3 \pm 8.3 \%$ in control cultures, and $\sim 55 \%$ of postnatal round neurons survived after 3 DIV regardless of the presence of the factor in the culture. Thus, the pattern of bFGF effect on round neurons clearly differed from that observed with P-neurons. NT-3 caused some increase in the survival of E18 round neurons and small P5 round neurons. The former was an expected result because NT-3 is essential for the survival of round neurons that will supply proprioceptive afferents to skeletal muscle spindles at $\sim$ E17-E18 (Ernfors et al., 1994). BDNF appeared toxic to large P5 round neurons, in agreement with other reports (Koh et al., 1995) and references therein (Fig. 4B, right). Neither NT-3 (10 ng/ml) nor BDNF (50 ng/ml) had any observable effect on the survival of embryonic or postnatal P-neurons (Fig. 4B).

\section{Expression of NGF and bFGF receptors in embryonic and postnatal P-neurons}

We studied by immunofluorescence microscopy the expression in P-neurons of Trk- $A$ and the high-affinity bFGF receptor ( $f g$ or FGF-receptor 1) before, during, and after the switch in trophic 
A

Figure 4. Differential effects of NGF, bFGF, NT-3, and BDNF on the survival of round and P-neurons of the DRG in culture. The experiments were performed at developmental stages at which the differences in the requirements for NGF or bFGF by P-neurons are most salient (E18 and P5) and show that the switch of survival requirements from NGF to bFGF was restricted to P-neurons. $A$, Average percentage ( \pm SEM) survival of E18 and P5 round neurons after 3 DIV (open bars), relative to their number at 1 DIV (taken as $100 \%$ ), in the presence of $50 \mathrm{ng} / \mathrm{ml}$ NGF or $10 \mathrm{ng} / \mathrm{ml} \mathrm{bFGF.} \mathrm{Round} \mathrm{neu-}$ rons were lumped into a single group $(R)$ at E18 and subclassified into small $(S ;<15 \mu \mathrm{m})$, medium $(M ; 15-26 \mu \mathrm{m})$, and large $(L ;>26 \mu \mathrm{m})$ neurons at P5. P-neuron data were included for comparison (hatched bars). The control group received no trophic factors. NGF dramatically enhanced the survival of E18 round and P-neurons (3 replications). The effect of NGF on P5 round neurons of any size group was mild, but larger than that observed on P5 P-neurons. bFGF promoted the survival of E18 round neurons, but not of P5 round neurons. $B$, Percentage survival of E18 and P5 P-neurons and round neurons after 3 DIV with NT-3 (10 $\mathrm{ng} / \mathrm{ml})$ or BDNF (50 ng/ml). NT-3 had no effect on the survival of E18 or P5 P-neurons, and slightly enhanced that of round neurons (E18 and small P5). BDNF was rather detrimental to P-neurons and large P5 round neurons (2 replications). Statistically significant differences between a given treatment and the control are labeled with * (Pneurons data) or ** (round neurons data) (ANOVA; Tukey post hoc test; $p=0.05)$.

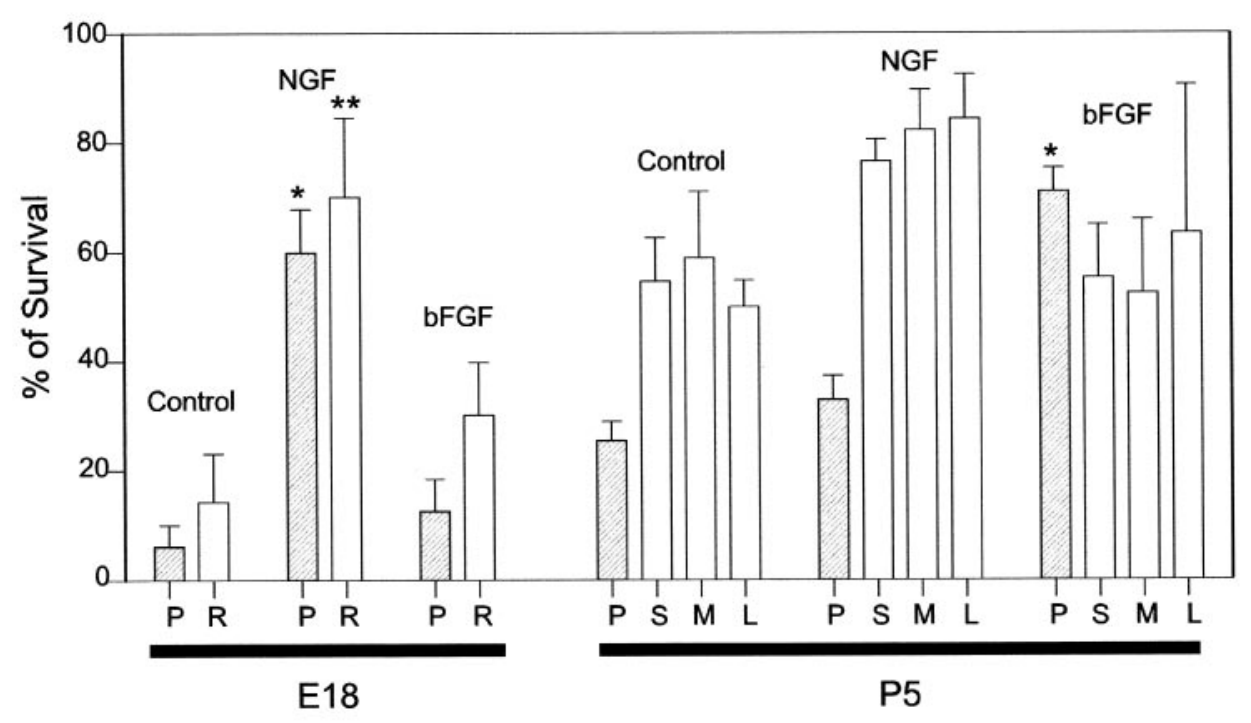

B

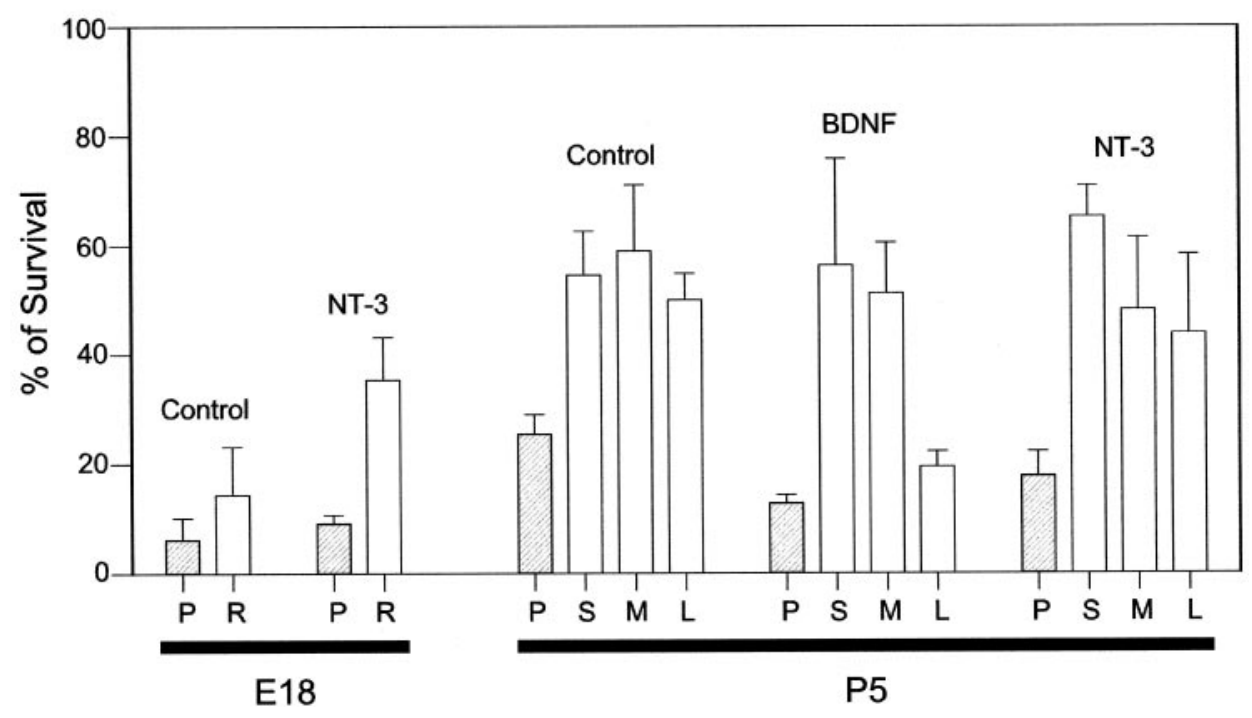

requirements. These experiments addressed the important point that if Trk- $A$ and $f l g$ are to mediate the survival-promoting effect of NGF and bFGF, respectively, then they must be present in the membrane of P-neurons at the appropriate times during development. Figure 5 illustrates representative examples of the expression of $\operatorname{Trk}-A$ and $f l g$ immunoreactivity in $\mathrm{P}$-neurons, as observed at the ages E18, P2, and P6. In all cases, the immunolabeling experiments were performed after 1 DIV. The expression of $\operatorname{Trk}-A$ or $f g$ qualitatively mirrored the change in the requirements for their corresponding ligands (three experimental replications). Thus, during the embryonic period in which only NGF enhanced survival (E18-E20), all P-neurons $(n=21$ cells) expressed $\operatorname{Trk}-A$, but none expressed $f l g$ (Fig. $5 A, B$ ). At P2, the age at which NGF and bFGF had similar survival promoting effects, a group of P-neurons expressed Trk- $A$ ( $n=12$ cells), whereas a different set expressed $f l g$ ( $n=14$ cells) (Fig. $5 C-F)$. We never observed coexpression of $\operatorname{Trk}-A$ and $f g$ in any given neuron or lack of expression of either receptor. However, we cannot rule out the possibility that lower levels of expression of those receptors, although functional, could be below the detection sensitivity of our immunolabeling technique. In fact, some degree of undetected coexpression might explain, at least partially, why the survival that was obtained with both NGF and bFGF during P2 did not approached the sum of the survivals obtained with those factors separately. At P5-P6, a stage at which only bFGF promoted survival, we detected expression of $f g$ but not $\operatorname{Trk}-A$ ( $n=23$ cells, from four experiments) (Fig. 5G,H). The mouse $\alpha-\operatorname{Trk}-A$ and rabbit $\alpha$-flg were used at 1:50 and 1:500 dilutions, respectively.

Expression of Trk- $A$ or $f l g$ was not restricted to P-neurons. A number of studies have shown expression of the Trk- $A$ mRNA and the protein in several types of rat sensory neurons (Mu et al., 1993; McMahon et al., 1994; White et al., 1996). Similarly, these neurons have been reported to express flg (Grothe and Wewetzer, 1996). In accord with those reports, we found Trk- $A$ immunoreactivity in round embryonic neurons and small and medium round postnatal neurons, and we found $f g$ immunoreactivity in medium and large cells (Fig. 5B, $G$ ). Coexpression of both recep- 


\section{Trk A}
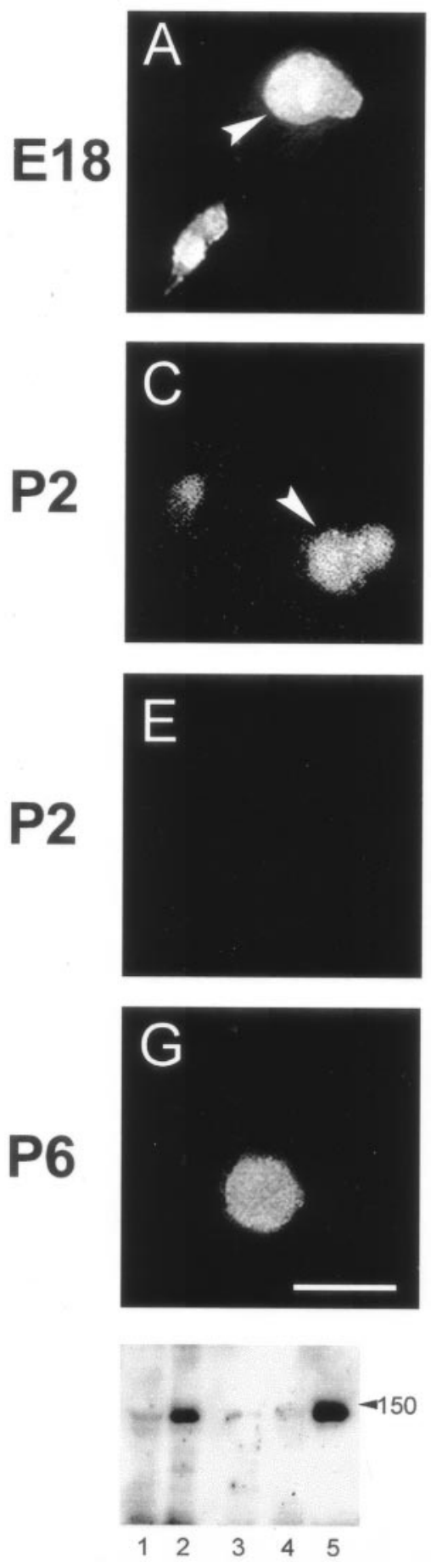

flg
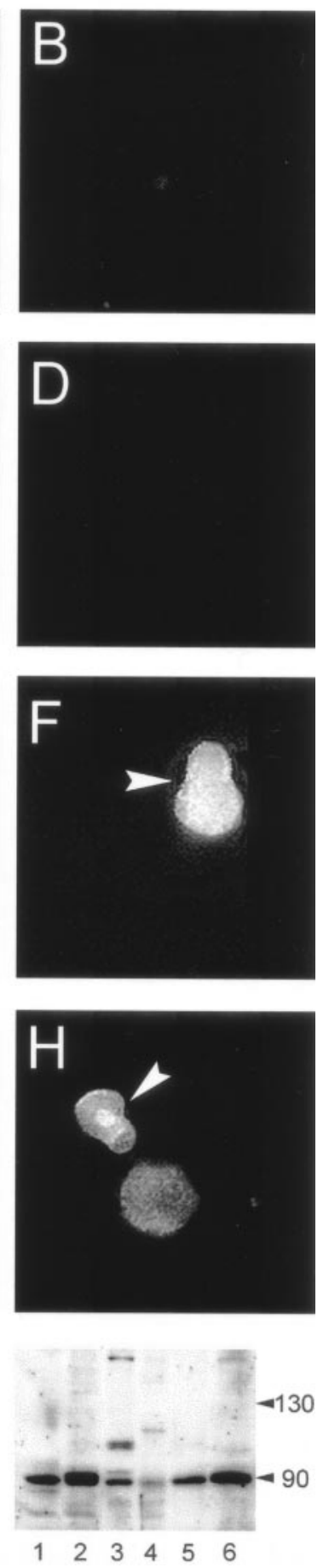

$\begin{array}{llllll}1 & 2 & 3 & 4 & 5 & 6\end{array}$
Figure 5. Expression of Trk- $A$ and $f g$ in P-neurons at different ages. Detection of Trk- $A$-like (left column) and flg-like (right column) immunoreactivity as revealed with mouse $\alpha-\operatorname{Tr} k-A$ (1:50) and rabbit $\alpha$-flg (1:500) antibodies, respectively, in cultures established from animals of ages shown on the left. Each row corresponds to a same view field but with the filter selected for FiTC (left) or rhodamine (right), which labeled the secondary antibodies (arrowheads indicate P-neurons). All experiments were performed $24 \mathrm{hr}$ after plating the neurons. E18 P-neurons were immunoreactive for $\operatorname{Trk}-A(A)$ but not $f g(B)$. At the age corresponding to the switchover of trophic requirement $(P 2)$, a set of P-neurons displayed $\operatorname{Tr} k-A$ immunoreactivity $(C)$ and a different set displayed $f g$ immunoreactivity $(F)$. No P-neurons were immunoreactive for both or for none of the proteins $(D, E)$. P6 P-neurons were immunoreactive for $f g$ tors appeared very infrequently in round neurons (an example is shown in Fig. $5 G, H)$. No switch in the expression from Trk- $A$ to $f g$ was observed in round neurons, although these experiments could not completely rule out that possibility.

Western blot data indicated that the antibodies specifically reacted with their targets. Thus, the monoclonal $\alpha$-Trk- $A$ labeled a single band of $\sim 140 \mathrm{kDa}$ in spinal cord, DRG, and whole brain and failed to react with proteins from muscle and kidney (Fig. 5, bottom left), in agreement with the expression of Trk-A in those tissues (Lomen-Hoerth and Shooter, 1995; Wheeler et al., 1998). The polyclonal $\alpha$-flg labeled a single band of $\sim 90 \mathrm{kDa}$ in $\mathrm{DRG}$, lung, spinal cord, heart, and brain (Fig. 5, bottom right), as expected from the literature (Perderiset et al., 1992; Hughes and Hall, 1993; Sugi et al., 1995). The presence of more than one band in skeletal muscle most probably reflected the antibody reaction with the $\mathrm{C}$-terminal epitope of truncated forms of FGFR-1 that was present in that tissue (Templeton and Hauschka, 1992).

\section{Requirement of bFGF by postnatal P-neurons in vivo}

To investigate whether the survival promoting effect of bFGF on $\mathrm{P}$-neurons that was observed in vitro also occurred in vivo, postnatal rats received daily intraperitoneal injections of an antibody against bFGF ( $\alpha-b F G F)$ during the days $\mathrm{P} 2-\mathrm{P} 5$ aimed at sequestering the factor that P-neurons needed from P2 onward. This strategy has been successfully used for studying the dependence of sensory neurons on NGF and other trophic factors (Carroll et al., 1992; Ruit et al., 1992) or NT-3 (Oakley et al., 1995; Zhou and Rush, 1995a; Lefcort et al., 1996). We compared the number of P-neurons in DRG cultures obtained from injected animals with their number in control cultures obtained from PBS-injected animals. If P-neurons did require bFGF in vivo, then there should be a deficit of those cells in cultures of antibody-injected animals. In agreement with this expectation, there was a substantial reduction in the number of P-neurons found in cultures obtained from antibody-injected animals, with a 2.4-fold reduction of their total number (Fig. 6A). The detection by immunoblot of circulating antibody shortly after its intraperitoneal injection gave support to our assumption that it reached the peripheral nervous system through the bloodstream (Fig. 6B). In addition, in cultures of antibody-injected animals, there was a marked reduction in the number of fibroblasts and glial cells, which were ubiquitous in cultures from control or PBS-injected animals. This further indicated that the circulating antibody effectively neutralized the endogenous bFGF, because those cell types require that factor for survival (Vescovi et al., 1993). Representative photographs of cultures from control and Ab-injected animals are shown in

$(H)$ but not $\operatorname{Trk}-A(G)$. Scale bar (shown in $G$ ): $A, B, 18 \mu \mathrm{m} ; C, D, 20 \mu \mathrm{m}$; $E, F, 15 \mu \mathrm{m}$; and $G, H, 30 \mu \mathrm{m}$. Bottom, Western blots assaying the expression of $\operatorname{Trk}-A$ (left) and flg (right) in different tissues with the antibodies used for neuronal immunolabeling. The lanes correspond to spinal cord (1), DRG (2), skeletal muscle (3), kidney (4), and brain (5) in left panel, and to DRG (1), lung (2), skeletal muscle (3), spinal cord (4), heart (5), and brain (6) in right panel (20 $\mu \mathrm{g}$ of tissue proteins seeded in each lane). The monoclonal $\alpha$-Trk- $A$ labeled a single band that corresponded to the molecular weight (MW) of $\operatorname{Trk}-A(\sim 140 \mathrm{kDa})$. The rabbit $\alpha$-flg labeled a single band corresponding to the estimated MW of FGFR-1 $(\sim 90 \mathrm{kDa})$ in all tissues, except in skeletal muscle. The extra bands in skeletal muscle presumably reflected the antibody reaction with the C-terminal epitope of truncated forms of FGFR-1 expressed in that tissue (Templeton and Hauschka, 1992). 
A
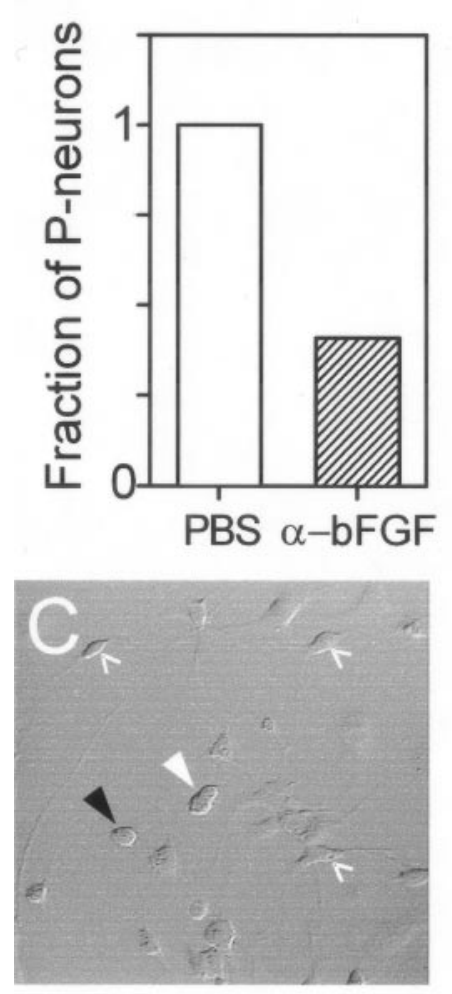

PBS
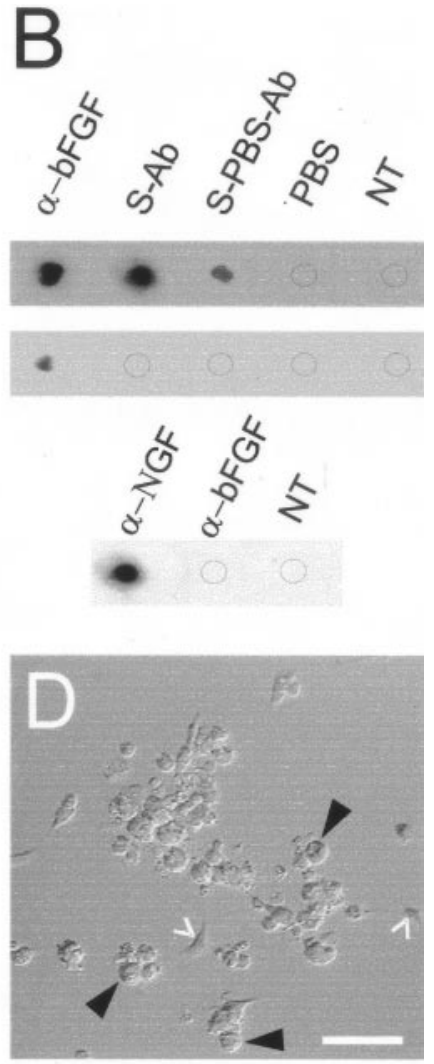

$\alpha-\mathbf{b F G F}$
Figure 6. Effect in vivo of an antibody against $\alpha-b F G F$ on the number of P-neurons during the early postnatal period. $A$, The proportion of P-neurons in culture was 2.4-fold smaller in $\alpha-b F G F$-injected animals $(1.3 \%)$ as compared with controls $(3.17 \%)$. Number of P-neurons and round neurons counted were 45 of 3458 and 78 of 2463 , respectively. $B$, Immunodot blots showing that the $\alpha-b F G F$ can be found in rat serum $1 \mathrm{hr}$ ( first row), but not $12 \mathrm{hr}$ (second row), after its intraperitoneal administration. Each dot illustrates the result of treating a substrate of pure human bFGF (250 ng in $10 \mu \mathrm{l})$ with $\alpha-b F G F(1: 50)$ as positive control, or serum (without dilution) from animals treated with $\alpha-b F G F$ for $3 \mathrm{~d}$ plus one extra dosis $1 \mathrm{hr}$ before bleeding $(S-A b)$, PBS for $3 \mathrm{~d}$ plus one dosis of $\alpha-b F G F 1 \mathrm{hr}$ before bleeding (S-PBS-Ab), PBS for $3 \mathrm{~d}(P B S)$, or from untreated control animals $(N T)$. The immunodot blot reaction was revealed with a secondary antibody. The reaction reliably detected circulating $\alpha-b F G F 1 \mathrm{hr}$ after the last antibody injection but not after $12 \mathrm{hr}$. The antibody $\alpha-b F G F$ did not cross-react with mNGF 7S (25 ng/ $\mu$ l) (third row). $C, D$, Representative Nomarski-interference photographs of cultures obtained from rats that received one injection per day of PBS (100 $\mu \mathrm{l})(C)$ or $\alpha-b F G F(100 \mu \mathrm{l}, 1: 10)(D)$ during postnatal days $2-4$. The number of non-neuronal cells that depend on the supply of bFGF (glia and fibroblasts) was greatly reduced after the antibody treatment. White arrowhead, P-neuron; black arrowheads, round neuron; white angles, nonneuronal cells (fibroblasts or glia). At a 1:50 dilution, the antibody injection produced a minor reduction in the number of P-neurons. Scale bar, $50 \mu \mathrm{m}$. Cultures were plated in video microscopy chambers and kept in MEM10 for $24 \mathrm{hr}$, and the media was replaced by PBS for image acquisition $24 \mathrm{hr}$ later. Throughout the experiment, the cultures were maintained at $37^{\circ} \mathrm{C}$ and supplemented with $10 \mathrm{ng} / \mathrm{ml} \mathrm{bFGF}$ to support the survival of P-neurons.

Figure 6, $C$ and $D$. In addition to the reduced number of P-neurons and non-neuronal cells, the culture of Ab-treated animals differed from the typical cultures in several respects. The neurons had a grainy profile and tended to form clusters. In agreement with the lack of effect of bFGF on postnatal round neurons (Fig. 4A), their number did not seem to be significantly reduced in antibody-injected animals. However, they had thinner nerve fibers at the time of the DRG isolation, and therefore we cannot exclude more subtle effects perhaps attributable to the loss of non-neuronal cells (Jessen and Mirsky, 1999) and references therein.

\section{Innervation of peripheral tissues by P-neurons}

To further characterize the P-neuron sensory subpopulation, we studied to which peripheral tissues they provide afferent innervation. Several potential targets, such as skin, subcutaneous tissue, skeletal muscle, and joints were injected in vivo with the intensely fluorescent lipophilic neuroanatomical tracer DiI, which is selectively taken up by nerve cell terminals and diff uses centrally along the neuronal membranes (Schroeder and McCleskey, 1993). If P-neurons peripheral terminals selectively innervate any of the above targets, then the tracer should eventually reach the somata of P-neurons only after the injection of the specific target(s).

Inspection of DRG cultures prepared 2-3 d after DiI administration into a single peripheral site revealed labeled P-neurons only after skeletal muscle dye injections. Of 20 labeled neurons found in that case, seven were P-neurons (of an estimated population of $100 \mathrm{P}$-neurons), a reasonable yield of our minimum dye injection protocol (see Materials and Methods) (Fig. 7A). Single injections into skin $(n=6)$, subcutaneous tissue $(n=13)$, or joints $(n=10)$ only labeled round neurons. Injections of a higher concentration of DiI into a large fraction of the subcutaneous tissue $(\sim 30-40 \%)$ confirmed the lack of innervation of that tissue by P-neurons (Fig. $7 B$ ). As expected, that dye application yielded a larger number of labeled round neurons (Fig. $7 C$ ). In these experiments, the phenotype of P-neurons was accurately identified under phase contrast before obtaining the images, as illustrated in Figure 7.

Sensory innervation of skeletal muscle includes large myelinated fast-conducting and unmyelinated slow-conducting fibers (Zhou and Rush, 1995b). Our data suggest that P-neurons correspond to the second group. First, P-neurons showed no immunoreactivity for $200 \mathrm{kDa}$ protein subunit of neurofilaments, an exclusive marker of large myelinated fast-conducting sensory neurons (Lawson et al., 1984) (Fig. 7D). As expected, the antibody clearly labeled the large round neurons present in the same cultures. Second, the survival of embryonic fast-conducting myelinated muscle afferents (proprioceptors innervating muscle spindles) both in vivo and in vitro require NT-3 (Hory-Lee et al., 1993; Oakley et al., 1995, 1997; Wright et al., 1997), a neurotrophin that had no effect on the survival of P-neurons (Fig. 4B). Lastly, the size of proprioceptors is among the largest of sensory neurons, whereas P-neurons fall into the medium size group.

\section{Coexpression of substance $\mathbf{P}$ and other markers in P-neurons}

We have previously shown that the somata of postnatal neuritefree P-neurons in culture display immunoreactivity for SP (Acosta and López, 1999), a peptide that has been involved in the transmission of nociceptive stimuli (Holland and Goldstein, 1990). Here, we have confirmed and extended those results. Every single postnatal P-neuron present in the culture was immunoreactive for SP ( $n=50$, replicated at least in eight assays). As is well known, SP immunoreactivity can be found in other sensory neuron subpopulations, particularly in small round neurons (O'Brien et al., 1989; Nothias et al., 1993). Unlike P-neurons, however, only a fraction of those subpopulations expressed the peptide (data not shown). Interestingly, two replications of 

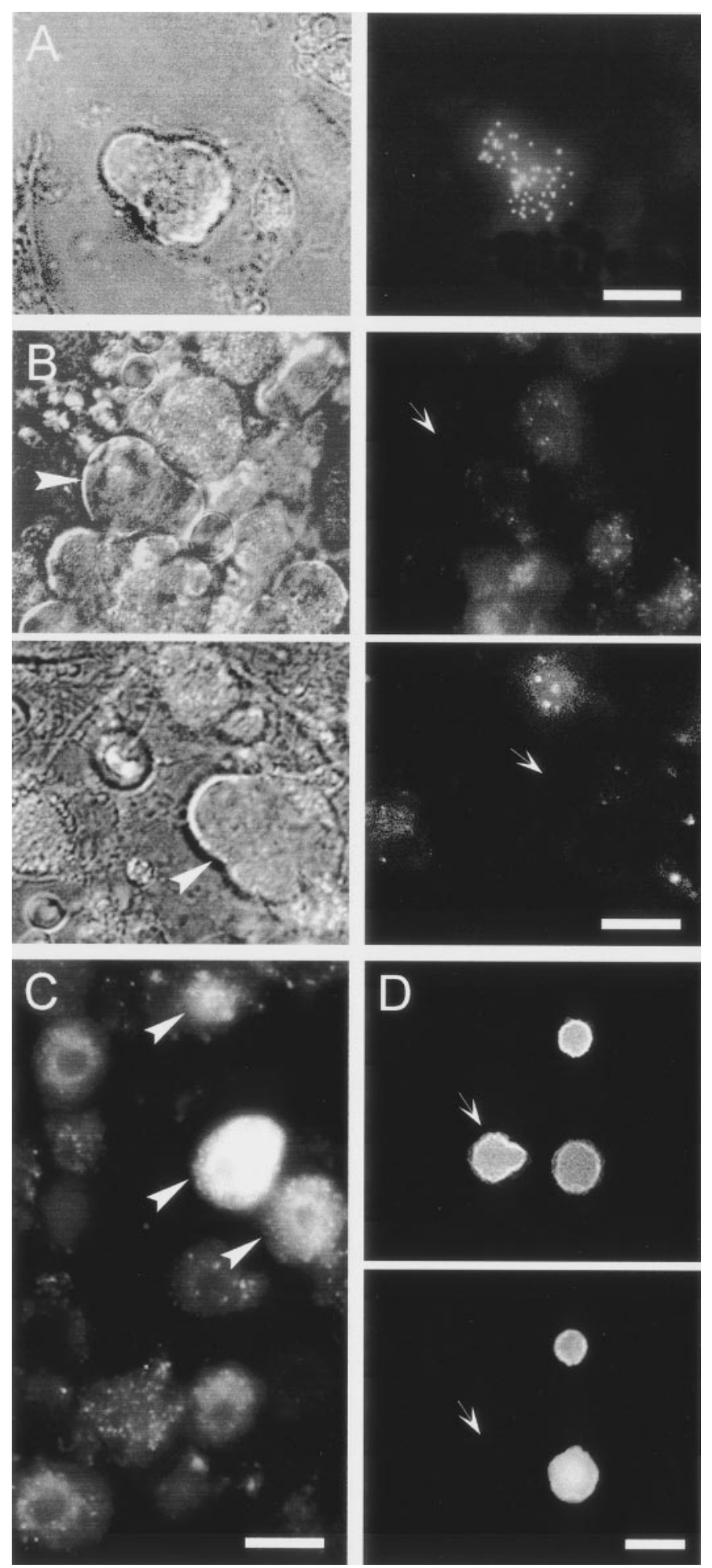

Figure 7. Peripheral target innervated by P-neurons as revealed by the retrograde transport of the lipophilic fluorescent neuronal tracer DiI (1\%) injected into several tissues of newborn rats (P2). Cultures of DRG were examined for fluorescently labeled neurons (arrowheads) 3-4 d after a single injection of DiI. $A$, Phase contrast Nomarski photograph (left $)$ and patchy pattern of DiI labeling (right) of the same P-neuron after the injection of a single $2 \mu \mathrm{l}$ of DiI in the main muscle mass of both hindlegs. $B$, Dye injections into skin or subcutaneous targets never labeled P-neurons. Phase contrast photographs of two P-neurons (left, arrowheads) lacking DiI labeling (right, arrows) after large DiI injections at high concentration into several cutaneous sites of a rat. $C$, Round sensory double-labeling experiments showed that whenever embryonic P-neurons were immunoreactive for Trk- $A$, they lacked SP immunoreactivity $(n=12)$ (Fig. $8 A, B)$. In contrast, SP and flg strictly coexpressed in postnatal P-neurons $(n=8)$ (Fig. $8 C, D)$. Thus, in addition to their unique requirement of NGF and bFGF, this one-to-one correlation between $f l g$ and SP expression was a unique marker further typifying these cells. Of the round neurons that expressed SP, only a minor fraction ( $7 \%$; 2 of 29 neurons) showed immunoreactivity for $\mathrm{flg}$ (Fig. $8 E, F$ ). Conversely, round neurons expressing $f l g$ lacked immunoreactivity for SP (data not shown).

\section{Potential sources of bFGF}

Like other primary sensory neurons, the cell bodies of P-neurons are located within the DRG itself; their pseudounipolar axons project centrally and peripherally to the spinal cord and, as shown before, to skeletal muscle, respectively. Assessing whether the sites with which $\mathrm{P}$-neuron somas or fibers anatomically relate (DRG, spinal cord, skeletal muscle) are potential sources of bFGF is important to hypothesize on how the switch in trophic dependence might correlate with developmental events, such as the establishment of innervation. The presence of bFGF was determined in the relevant peripheral tissues using Western blots at different developmental stages (E20, P1, and P5) (Fig. 9A). bFGF was present in skeletal muscle as well as in the spinal cord and the DRG at all ages tested. Interestingly, the highest expression of the factor in muscle coincided with the time at which all P-neurons became bFGF-dependent. A more indirect evidence of the bFGF presence in the tissues examined above was obtained from a set of separate immunocytochemical experiments that were performed during the postnatal stage at which that factor promoted survival (P3-P6). The representative data of Figure 9 show that neurons and glial cells of the DRG (Fig. 9B,D) and spinal cord (Fig. 9E), as well as skeletal muscle fibers (Fig. 9C), were immunoreactive for bFGF. In sharp contrast, P-neuron themselves or fibroblasts completely lacked immunolabeling (Fig. $9 B, D)$. These data indicate that P-neurons may potentially obtain bFGF from several types of cells. Our data show that the factor is available in sites reachable by P-neurons at the time they become bFGF-dependent.

\section{DISCUSSION}

Distinguishing a group of sensory neurons as a distinct, homogenous subpopulation usually requires determining several characteristics of the cells, with their specific requirements of trophic factors during development being a major defining criterion (Cameron et al., 1992; Perl, 1992; Snider, 1994; Lewin and Barde, 1996). We report a set of properties of the cell group that we have referred to as P-neurons, which, together with our previous study (Acosta and López, 1999), indicate that they constitute a distinct subpopulation of the rat DRG. A defining feature of P-neurons

\section{$\leftarrow$}

neurons from the same animal in $B$ labeled with DiI. Round labeled neurons (arrowheads) were also observed after injecting a very small volume $(3 \mu \mathrm{l})$ of a low concentration of DiI into a single cutaneous site (data not shown). $D$, Photographs of the same view field after the treatment with antibodies against the $\beta$-tubulin isotype III (top) and the $200 \mathrm{kDa}$ neurofilament protein (bottom). P-neurons showed no immunoreactivity for the $200 \mathrm{kDa}$ neurofilament (arrows), whereas some round neurons were labeled. All neurons were positive for the $\beta$-tubulin isotype III, which clearly delineated the soma shape. Scale bars: $A, D, 20 \mu \mathrm{m} ; B$, $18 \mu \mathrm{m} ; C, 15 \mu \mathrm{m}$. The data were replicated three to four times. 

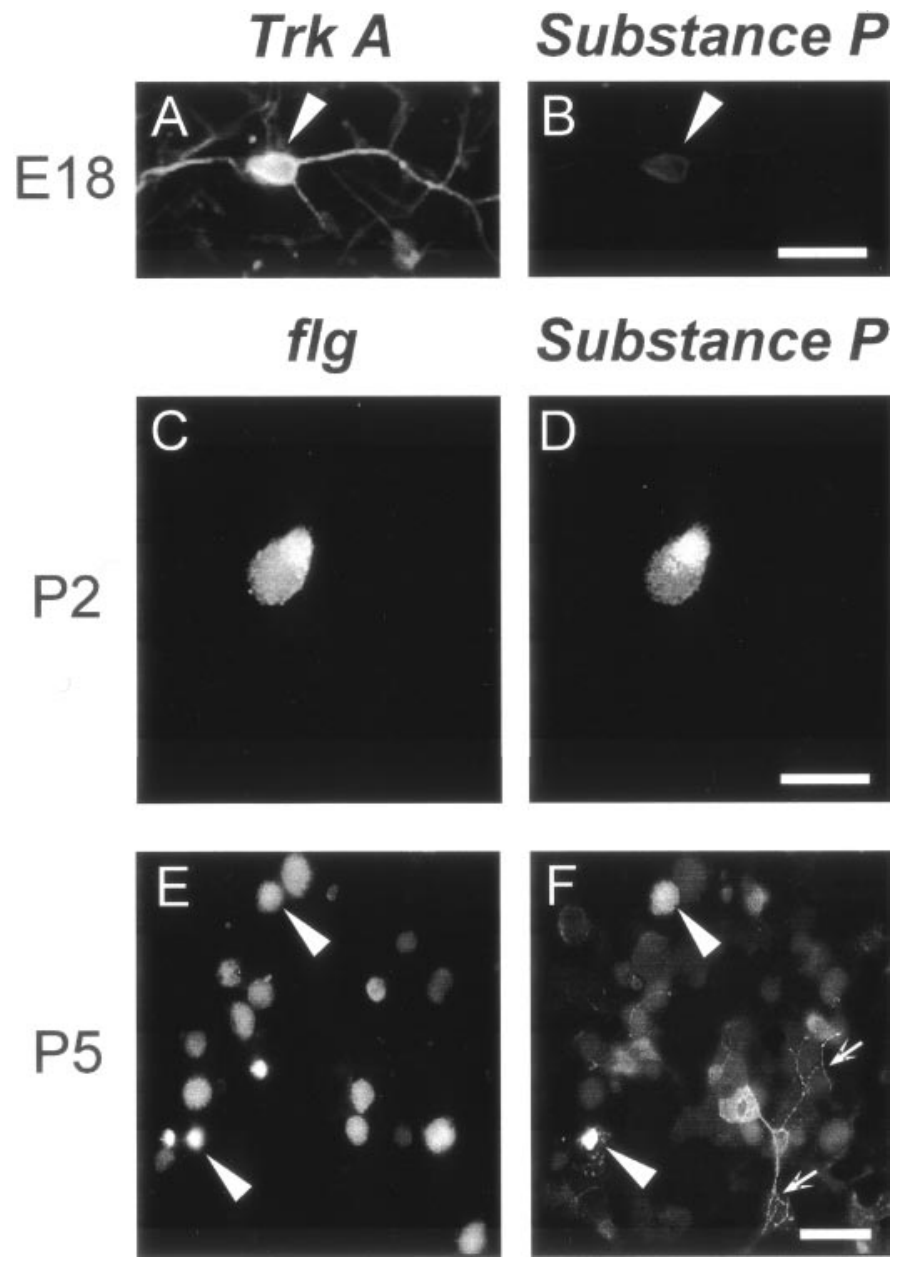

Figure 8. Substance P expression strictly paralleled the expression of $f l g$ in cultured P-neurons, as illustrated by double-labeling immunofluorescence experiments. Left column shows examples of Trk-A (top row) or flg (other rows) immunoreactive neurons, and right column shows examples of substance P (SP) immunoreactive neurons. The right and left panels in each row show the same view field. At E18 (top row), all P-neurons (arrowheads) expressed Trk- $A(A)$ and none expressed SP immunoreactivity $(B)(n=12)$. A large number of round neurons were also immunoreactive for $\operatorname{Trk}-A$ (data not shown). At this stage there was no detectable immunolabeling for $f g$ in $\mathrm{P}$-neurons. At $\mathrm{P} 2$ (middle row), the P-neurons that were immunoreactive for $f g(C)$ were also immunoreactive for SP $(D)(n=8)$. In contrast, those negative for $f g$ were also negative for SP (data not shown). Only $f l g$-positive P-neurons contained substance P. In non-P-neurons, coexpression of $f l g$ and SP was infrequent $(\sim 7 \%)$. An example from P5 animals is shown in $E$ and $F$. Arrowheads indicate round neuron somata that coexpressed $f l g$ and SP, out of 29 round neurons present in the field. Arrows indicate axons that showed SP, but not $f g$, immunoreactivity. In all cases, we used a rat monoclonal antibody against SP at a dilution of 1:20. Scale bars: $A, B, 15 \mu \mathrm{m} ; C, D, 20 \mu \mathrm{m} ; E$, $F, 50 \mu \mathrm{m}$.

was their requirement of NGF prenatally and bFGF postnatally for survival during development, because no other type of sensory neurons studied here or elsewhere depended on that specific sequence of trophic factors (Vescovi et al., 1993; Grothe and Wewetzer, 1996; Ogilvie et al., 2000). Originally reported by Buchman and Davies (1993), this pattern of trophic dependence has been increasingly recognized in sensory (Molliver et al., 1997) and other neuronal types (Davies, 1994). For instance, mouse trigeminal neurons prenatally switch from BDNF-NT-3 to NGF (Buchman and Davies, 1993), and IB4-positive mouse sensory
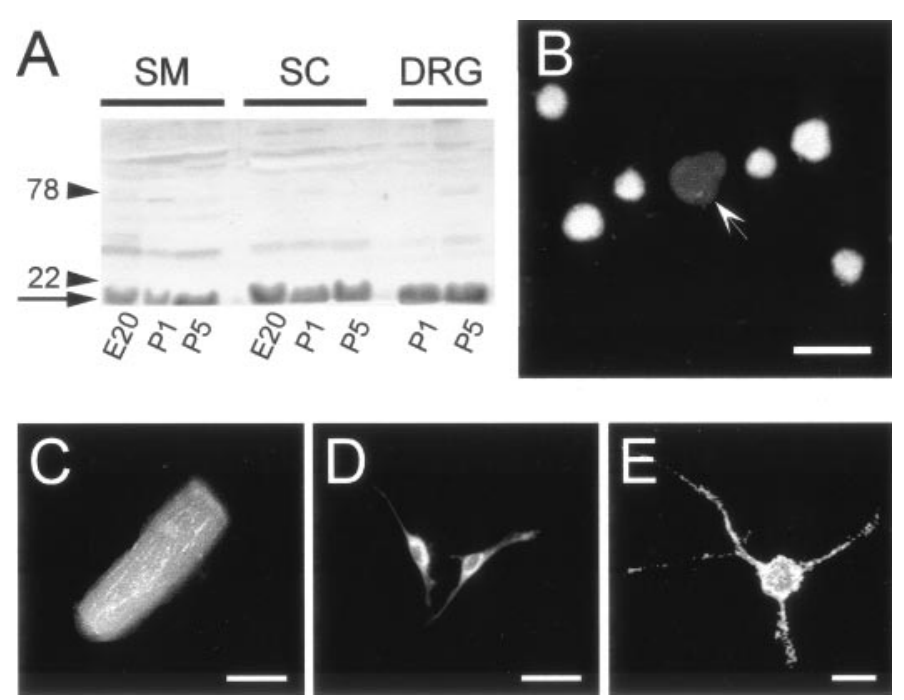

Figure 9. Expression of bFGF immunoreactivity at sites with which P-neurons relate anatomically, revealing potential sources of bFGF at the time it was required for P-neuron survival. All tissues were isolated from animals of age $\mathrm{P} 3-\mathrm{P} 5$. A, Western blot showing the expression pattern of bFGF in skeletal muscle $(S M)$, spinal cord $(S C)$, and $D R G$ at ages indicated under the corresponding lanes. Labeled bands of $\sim 18 \mathrm{kDa}$ (arrow), the MW of bFGF, indicate expression of that protein in all of those tissues. The locations of 22 and $78 \mathrm{kDa}$ MW markers in a gel run in parallel are indicated by arrowheads and corresponding MW numbers. $B$, DRG cultured cells. Some round neurons expressed bFGF immunoreactivity. In contrast, P-neurons themselves were always negative (arrow). $C$, At $\mathrm{P} 3,90 \%$ of skeletal muscle fibers, the presumptive innervation target of P-neurons according to our data (Fig. 7), were clearly positive for bFGF. A representative example is shown here. $D$, Glial cells (presumptive type-2 astrocytes, identified with double staining with an antibody against $\alpha$-GFAP) (data not shown) from the same ganglia used in $A$ were also immunolabeled for bFGF. $E$, Photograph of a bFGF-positive neuron from the spinal cord. Experiments were performed using a mouse monoclonal antibody $(\alpha-b F G F)$ at 1:200 dilution. Scale bars: $B, 40 \mu \mathrm{m} ; C$, $20 \mu \mathrm{m} ; D, 100 \mu \mathrm{m} ; E, 15 \mu \mathrm{m}$.

neurons switch from NGF to GDNF early after birth (Molliver et al., 1997). The need of more than a trophic factor, either sequentially or simultaneously, has also been strongly implied by work done in null mutants for neurotrophins or their receptors (White et al., 1996; Liebl et al., 1997). P-neurons specifically express $\operatorname{Trk}-A$ (E18) or $f l g$ (P5) at the ages at which their respective ligands act as sole survival factors, a correlation suggesting that the membrane exchange of the relevant receptors may be linked to the regulation of the trophic switch in vivo, as hypothesized elsewhere (Hashino et al., 1999; Baudet et al., 2000). It is at present unclear to what extent NGF and bFGF act on overlapping groups of P-neurons.

Like most developing DRG neurons, embryonic P-neurons depend on NGF (Levi-Montalcini and Angeletti, 1968; Kucera et al., 1995; Lewin and Barde, 1996) and become independent of it shortly after birth. However, they have not been previously identified as a specific group depleted after prenatal NGF deprivation. This treatment causes the loss of most small diameter neurons, presumably peptidergic, and mediating nociceptive functions in the adult (Davies et al., 1987; Lewin and Mendell, 1993; Snider, 1994). From our data, P-neurons do not appear to be contemplated in that group. The former represent $\sim 70 \%$ of the total population, are claimed to express SP or CGRP, and mostly innervate skin (for review, see Snider, 1994), whereas the medium size P-neurons contribute a relatively small fraction, have a dif- 
ferent morphological phenotype in culture, do not express SP whenever they express $\operatorname{Trk}-A$, and innervate skeletal muscle but not cutaneous tissue (see below). This last finding is especially interesting in view of the fact that embryonic NGF-dependent neurons are assumed to include most nociceptors, despite being presently unclear whether muscle nociceptors require that neurotrophin (Lewin and Barde, 1996; Snider and McMahon, 1998). With regard to SP expression in P-neurons, it was detected at times that closely agree with previous findings in the rat DRG (Hall et al., 1997).

This is the first report, as far as we are aware, showing a clear survival-promoting effect of bFGF on peripheral sensory neurons. Previous studies reported a minor effect, if any, on the survival of chick DRG neurons (Eckenstein et al., 1990; Oppenheim et al., 1992), whereas it clearly acts as survival factor on central neurons (Beck et al., 1993; Grothe and Wewetzer, 1996). Most commonly, bFGF has been found to be a powerful mitogen and differentiating factor (Birren and Anderson, 1990; Birren et al., 1993; Vescovi et al., 1993; Vaccarino et al., 1999). A strong indication that bFGF is required in vivo for the survival of $\mathrm{P}$-neurons is the large reduction in the number of those cells in newborn animals injected with the antibody against that factor. In particular, our result rules out that the dependence on bFGF observed in vitro results from the axotomy caused by tissue dissociation (Ji et al., 1995).

Our data fit only partially into the classical view that the survival of primary sensory neurons during development depends on the obtention of specific target-derived trophic factors by their growing axons (Levi-Montalcini and Angeletti, 1968; Lewin and Barde, 1996). P-neurons depend on NGF mostly before the development of target innervation by growing sensory axons (Reynolds et al., 1991; Coggeshall et al., 1994) (but see Mirnics and Koerber, 1995). Their requirement of NGF better correlates with the period of naturally occurring death, which peaks between E15 and E19, and is over just after birth. This conforms to the more recent notion that NGF is required by embryonic sensory neurons during the period of massive neuronal death, supplied by sources other than the peripheral targets, before their innervation (Coggeshall et al., 1994; Davies, 1997; Wetts and Vaughn, 1998). Accordingly, Trk genes (receptors for neurotrophins) are expressed early in development (Mu et al., 1993). Although we do not know whether P-neurons require NGF before E18, the factor appears to regulate their survival over a relatively extended time (E18-P2). One possible early source of trophic factors is the spinal cord (Snider et al., 1992; Fitzgerald et al., 1993; Coggeshall et al., 1994). Unlike NGF, the onset of bFGF effect occurs at an age in which sensory axons have reached skeletal muscle fibers, a target of P-neurons innervation (see below) (Coggeshall et al., 1994). Consistent with the idea of target-derived factor, bFGF is present in skeletal muscle at P3$\mathrm{P} 4$, although it is also found in neuronal and glial cells of the spinal cord and the DRG, as shown by others (Moore et al., 1991; Ji et al., 1995; Grothe et al., 1997).

The notion of trophic switch implies that exactly the same cells initially requiring some trophic factor subsequently need another. No conclusive proof of this has been possible for two main reasons (Birren et al., 1993; Molliver et al., 1997; Enokido et al., 1999; Enomoto et al., 2000): (1) the neurons requiring each trophic factor might be generated in different waves of neurogenesis when the switch occurs very early in development, and (2) the lack of a property, or of a marker uniquely identifying a single subpopulation of living neurons. Although this study does not show a trophic switch in a single neuron, it leaves little room for an alternative explanation. Both NGF and bFGF requirements occurred after the termination of neurogenesis, and the phenotype of P-neurons allowed their unequivocal identification in culture. Moreover, the stable proportion of P-neurons over ages E18-P5, together with the specific effects of NGF and bFGF at E18 and P5, respectively, would imply that if the switch occurred in different groups, then NGF-dependent P-neurons must differentiate into round cells postnatally, whereas a matching number of separate, round neurons must differentiate into bFGFdependent P-neurons. This speculation and the additional requirement that those two unrelated subpopulations should display a coordinated change in their sensitivity to the survival factors (Fig. 3) seem highly unreasonable.

Additional features distinguish the group of P-neurons. They project to skeletal muscle but not skin or joints. They are, however, different from the proprioceptors innervating muscle spindles. These are large, express the $200 \mathrm{kDa}$ neurofilament but not peptides, and require NT-3 for survival during embryonic life (Hory-Lee et al., 1993; Kucera et al., 1995; Zhou and Rush, 1995b). P-neurons are smaller, contain SP but not the $200 \mathrm{kDa}$ neurofilament, and do not require NT-3. Thus, they are likely to fall into the group of unmyelinated muscle afferents (Abrahams, 1986; Mense, 1996), although we cannot exclude projections to visceral targets. Interestingly, and consistent with our data, chick embryonic muscle sensory neurons require NGF (Hory-Lee et al., 1993), and adult muscle afferents only rarely express Trk- $A$ (McMahon et al., 1994). The expression of the pain-related peptide SP in P-neurons merits some comments. First, the coexpression of $f g$ and SP is a specific marker of postnatal P-neurons. Second, it suggests that they might have a nociceptive function in view of the fact that that all SP-containing sensory neurons have been reported to respond to noxious stimuli, and mostly project to deep, noncutaneous peripheral targets (Levine et al., 1993; Zheng and Lawson, 1994; Lawson et al., 1997). P-neurons might represent a subset of a larger subpopulation, of which only a fraction adopts a pear shape, and perhaps included in some group of sensory afferents previously studied. Nonetheless, this is the first study that characterizes them as a specific group. On the basis of this report and our previous work, we hypothesize that P-neurons represent nociceptors of skeletal muscle for which function could be strongly regulated by enkephalins (Acosta and López, 1999). Alternatively, they might correspond to fine afferents involved in SP-mediated, circulatory reflexes (Kniffeki et al., 1981; Wilson and Hand, 1997).

\section{REFERENCES}

Abe K, Saito H (2000) Neurotrophic effect of basic fibroblast growth factor is mediated by the p42/p44 mitogen-activated protein kinase cascade in cultured rat cortical neurons. Brain Res Dev Brain Res 122:81-85.

Abrahams V (1986) Group III and IV receptors of skeletal muscle. Can J Physiol Pharmacol 64:509-514.

Acosta C, López H (1999) $\delta$ opioid receptor modulation of several voltage-dependent $\mathrm{Ca}^{2+}$ currents in rat sensory neurons. J Neurosci 19:8337-8348.

Baudet C, Mikaels A, Westphal H, Johansen J, Johansen T, Ernfors P (2000) Positive and negative interactions of GDNF, NTN and ART in developing sensory neuron subpopulations, and their collaboration with neurotrophin. Development 127:4335-4344.

Beck KD, Knusel B, Hefti F (1993) The nature of the trophic action of brain-derived neurotrophic factor, des(1-3)-insulin-like growth factor-1, and basic fibroblast growth factor on mesencephalic dopaminergic neurons developing in culture. Neuroscience 52:855-866.

Berg MM, Sternberg DW, Parada LF, Chao MV (1992) K-252a inhibits nerve growth factor-induced trk proto-oncogene tyrosine phosphorylation and kinase activity. J Biol Chem 267:13-16. 
Birren SJ, Anderson DJ (1990) A v-myc-immortalized sympathoadrenal progenitor cell line in which neuronal differentiation is initiated by FGF but not NGF. Neuron 4:189-201.

Birren SJ, Lo L, Anderson DJ (1993) Sympathetic neuroblasts undergo a developmental switch in trophic dependence. Development 119:597-610

Buchman VL, Davies AM (1993) Different neurotrophins are expressed and act in a developmental sequence to promote the survival of embryonic sensory neurons. Development 118:989-1001.

Cáceres A, Mautino J, Kosik K (1992) Supression of MAP-2 in cultured cerebellar macroneurons inhibit minor neurite formation. Neuron 9:607-618.

Cameron AA, Pover CM, Willis WD, Coggeshall RE (1992) Evidence that fine primary afferent axons innervate a wider territory in the superficial dorsal horn following peripheral axotomy. Brain Res 575:151-154

Cardenas CG, Del Mar LP, Scroggs RS (1995) Variation in serotonergic inhibition of calcium channel currents in four types of rat sensory neurons differentiated by membrane properties. J Neurophysiol 74:1870-1879

Carroll SL, Silos-Santiago I, Frese SE, Ruit KG, Milbrandt J, Snider WD (1992) Dorsal root ganglion neurons expressing trk are selectively sensitive to NGF deprivation in utero. Neuron 9:779-788.

Caterina M, Julius D (1999) Sense and specificity: a molecular identity for nociceptors. Curr Opin Neurobiol 9:525-530.

Caterina M, Leffler A, Malmberg A, Martin W, Trafton J, Petersen-Zeitz K, Koltzenburg M, Basbaum A, Julius D (2000) Impaired nociception and pain sensation in mice lacking the capsaicin receptor. Science 288:306-313.

Coggeshall RE, Pover CM, Fitzgerald M (1994) Dorsal root ganglion cell death and surviving cell numbers in relation to the development of sensory innervation in the rat hindlimb. Brain Res Dev Brain Res $82: 193-212$

Davies AM (1994) Neurotrophic factors. Switching neurotrophin dependence. Curr Biol 4:273-276.

Davies AM (1997) Neurotrophin switching: where does it stand? Curr Opin Neurobiol 7:110-118

Davies AM, Bandtlow C, Heumann R, Korsching S, Rohrer H, Thoenen H (1987) Timing and site of nerve growth factor synthesis in developing skin in relation to innervation and expression of the receptor. Nature 326:353-358.

Dickenson AH, Sullivan AF, Knox R, Zajac JM, Roques BP (1987) Opioid receptor subtypes in the rat spinal cord: electrophysiological studies with mu- and delta-opioid receptor agonists in the control of nociception. Brain Res 413:36-44.

Eckenstein FP, Esch F, Holbert T, Blacher RW, Nishi R (1990) Purification and characterization of a trophic factor for embryonic peripheral neurons: comparison with fibroblast growth factors. Neuron 4:623-631.

Ehrhard PB, Otten U (1994) Postnatal ontogeny of the neurotrophin receptors trk and trkB mRNA in rat sensory and sympathetic ganglia. Neurosci Lett 166:207-210.

Enokido Y, Wyatt S, Davies AM (1999) Developmental changes in the response of trigeminal neurons to neurotrophins: influence of birthdate and the ganglion environment. Development 126:4365-4373.

Enomoto H, Heuckeroth RO, Golden JP, Johnson EM, Milbrandt J (2000) Development of cranial parasympathetic ganglia requires sequential actions of GDNF and neurturin. Development 127:4877-4889.

Ernfors P, Lee KF, Kucera J, Jaenisch R (1994) Lack of neurotrophin-3 leads to deficiencies in the peripheral nervous system and loss of limb proprioceptive afferents. Cell 77:503-512.

Everill B, Kocsis JD (1999) Reduction in potassium currents in identified cutaneous afferent dorsal root ganglion neurons after axotomy. J Neurophysiol 82:700-708.

Ferreira A, Caceres A (1992) Expression of the class III beta-tubulin isotype in developing neurons in culture. J Neurosci Res 32:516-529.

Fitzgerald M, Kwiat GC, Middleton J, Pini A (1993) Ventral spinal cord inhibition of neurite outgrowth from embryonic rat dorsal root ganglia. Development 117:1377-1384.

Gilabert R, McNaughton P (1997) Enrichment of the fraction of nociceptive neurones in cultures of primary sensory neurons. J Neurosci Methods 71:191-198.

Grothe C, Wewetzer K (1996) Fibroblast growth factor and its implications for developing and regenerating neurons. Int $\mathrm{J}$ Dev Biol 40:403-410.

Grothe C, Meisinger C, Hertenstein A, Kurz H, Wewetzer K (1997) Expression of fibroblast growth factor-2 and fibroblast growth factor receptor 1 messenger RNAs in spinal ganglia and sciatic nerve: regulation after peripheral nerve lesion. Neuroscience 76:123-135.

Hall AK, Ai X, Hickman GE, MacPhedran SE, Nduaguba CO, Robertson CP (1997) The generation of neuronal heterogeneity in a rat sensory ganglion. J Neurosci 17:2775-2784.

Hamill O, Marty A, Neher E, Sackmann B, Sigworth F (1981) Improved patch-clamp techniques for high-resolution current recording from cells and cell-free membrane patches. Pflügers Arch 39:85-100.

Harper AA, Lawson SN (1985) Conduction velocity is related to mor- phological cell type in rat dorsal root ganglion neurones. J Physiol (Lond) 359:31-46.

Hashino E, Dolnick RY, Cohan CS (1999) Developing vestibular ganglion neurons switch trophic sensitivity from BDNF to GDNF after target innervation. J Neurobiol 38:414-427.

Holland LN, Goldstein BD (1990) Changes of substance P-like immunoreactivity in the dorsal horn are associated with the "phasic" behavioral response to a formalin stimulus. Brain Res 537:287-292.

Honig MG, Hume RI (1989) Dil and diO: versatile fluorescent dyes for neuronal labelling and pathway tracing. Trends Neurosci 12:333-335.

Hory-Lee F, Russell M, Lindsay RM, Frank E (1993) Neurotrophin 3 supports the survival of developing muscle sensory neurons in culture. Proc Natl Acad Sci USA 90:2613-2617.

Hughes SE, Hall PA (1993) Immunolocalization of fibroblast growth factor receptor 1 and its ligands in human tissues. Lab Invest 69:173-182.

Jessen KR, Mirsky R (1999) Schwann cells and their precursors emerge as major regulators of nerve development. Trends Neurosci 22:402-410

Ji RR, Zhang Q, Zhang X, Piehl F, Reilly T, Pettersson RF, Hokfelt T (1995) Prominent expression of bFGF in dorsal root ganglia after axotomy. Eur J Neurosci 7:2458-2468.

Kniffeki K, Mense S, Schmidt R (1981) Muscle receptors with fine afferent fibers which may evoke circulatory reflexes. Circ Res 48:I25-31.

Koh JY, Gwag BJ, Lobner D, Choi DW (1995) Potentiated necrosis of cultured cortical neurons by neurotrophins. Science 268:573-575.

Koizumi S, Contreras ML, Matsuda Y, Hama T, Lazarovici P, Guroff G (1988) K-252a: a specific inhibitor of the action of nerve growth factor on PC 12 cells. J Neurosci 8:715-721.

Kucera J, Fan G, Jaenisch R, Linnarsson S, Ernfors P (1995) Dependence of developing group Ia afferents on neurotrophin-3. J Comp Neurol 363:307-320.

Lawson SN, Harper AA, Harper EI, Garson JA, Anderton BH (1984) A monoclonal antibody against neurofilament protein specifically labels a subpopulation of rat sensory neurons. J Comp Neurol 228:263-272.

Lawson SN, Crepps BA, Perl ER (1997) Relationship of substance P to afferent characteristics of dorsal root ganglion neurones in guinea-pig. J Physiol (Lond) 505:177-191.

Lefcort F, Clary DO, Rusoff AC, Reichardt LF (1996) Inhibition of the NT-3 receptor TrkC, early in chick embryogenesis, results in severe reductions in multiple neuronal subpopulations in the dorsal root ganglia. J Neurosci 16:3704-3713.

Levi-Montalcini R, Angeletti PU (1968) Nerve growth factor. Physiol Rev 48:534-569.

Levine JD, Fields HL, Basbaum AI (1993) Peptides and the primary afferent nociceptor. J Neurosci 13:2273-2286.

Lewin GR, Barde YA (1996) Physiology of the neurotrophins. Annu Rev Neurosci 19:289-317.

Lewin GR, Mendell LM (1993) Nerve growth factor and nociception. Trends Neurosci 16:353-359.

Liebl DJ, Tessarollo L, Palko ME, Parada LF (1997) Absence of sensory neurons before target innervation in brain-derived neurotrophic factor-, neurotrophin 3-, and TrkC-deficient embryonic mice. J Neurosci 17:9113-9121.

Lomen-Hoerth C, Shooter EM (1995) Widespread neurotrophin receptor expression in the immune system and other nonneuronal rat tissues. J Neurochem 64:1780-1789.

McMahon S, Armanini M, Ling L, Phillips H (1994) Expression and coexpression of Trk receptors in subpopulations of adult primary sensory neurons projecting to identified peripheral targets. Neuron $12: 1161-1171$

Mense S (1996) Group III and IV receptors in skeletal muscle: are they specific or polymodal? Prog Brain Res 113:83-100.

Mirnics K, Koerber HR (1995) Prenatal development of rat primary afferent fibers. I. Peripheral projections. J Comp Neurol 355:589-600.

Molliver D, Snider W (1997) Nerve growth factor receptor TrkA is down-regulated during postnatal development by a subset of dorsal root ganglion neurons. J Comp Neurol 381:428-438.

Molliver DC, Wright DE, Leitner ML, Parsadanian AS, Doster K, Wen D, Yan Q, Snider WD (1997) IB4-binding DRG neurons switch from NGF to GDNF dependence in early postnatal life. Neuron 19:849-861.

Moore JW, Dionne C, Jaye M, Swain JL (1991) The mRNAs encoding acidic FGF, basic FGF and FGF receptor are coordinately downregulated during myogenic differentiation. Development 111:741-748.

Mu X, Silos-Santiago I, Carroll SL, Snider WD (1993) Neurotrophin receptor genes are expressed in distinct patterns in developing dorsal root ganglia. J Neurosci 13:4029-4041.

Nothias F, Tessler A, Murray M (1993) Restoration of substance P and calcitonin gene-related peptide in dorsal root ganglia and dorsal horn after neonatal sciatic nerve lesion. J Comp Neurol 334:370-384.

Oakley RA, Garner AS, Large TH, Frank E (1995) Muscle sensory neurons require neurotrophin-3 from peripheral tissues during the period of normal cell death. Development 121:1341-1350.

Oakley RA, Lefcort FB, Clary DO, Reichardt LF, Prevette D, Oppen- 
heim RW, Frank E (1997) Neurotrophin-3 promotes the differentiation of muscle spindle afferents in the absence of peripheral targets. J Neurosci 17:4262-4274.

O’Brien C, Woolf CJ, Fitzgerald M, Lindsay RM, Molander C (1989) Differences in the chemical expression of rat primary afferent neurons which innervate skin, muscle or joint. Neuroscience 32:493-502.

Ogilvie JM, Speck JD, Lett JM (2000) Growth factors in combination, but not individually, rescue rd mouse photoreceptors in organ culture. Exp Neurol 161:676-685.

Oppenheim RW, Prevette D, Fuller F (1992) The lack of effect of basic and acidic fibroblast growth factors on the naturally occurring death of neurons in the chick embryo. J Neurosci 12:2726-2734.

Perderiset M, Courty J, Mereau A, Chevet E, Barritault D (1992) Purification of a heparin binding FGF receptor (HB-FGFR) from adult bovine brain membranes. Biochimie 74:1091-1096.

Perl ER (1992) Function of dorsal root ganglion neurons: an overview. In: Sensory neurons: diversity, development, and plasticity (Scott SA, ed), pp 3-23. New York: Oxford UP.

Reynolds ML, Fitzgerald M, Benowitz LI (1991) GAP-43 expression in developing cutaneous and muscle nerves in the rat hindlimb. Neuroscience 41:201-211.

Ruit KG, Elliott JL, Osborne PA, Yan Q, Snider WD (1992) Selective dependence of mammalian dorsal root ganglion neurons on nerve growth factor during embryonic development. Neuron 8:573-587.

Schmidt MF, Kater SB (1993) Fibroblast growth factors, depolarization, and substratum interact in a combinatorial way to promote neuronal survival. Dev Biol 158:228-237.

Schroeder JE, McCleskey EW (1993) Inhibition of $\mathrm{Ca}^{2+}$ currents by a $\mu$-opioid in a defined subset of rat sensory neurons. J Neurosci 13:867-873.

Silos-Santiago I, Molliver DC, Ozaki S, Smeyne RJ, Fagan AM, Barbacid M, Snider WD (1995) Non-TrkA-expressing small DRG neurons are lost in TrkA-deficient mice. J Neurosci 15:5929-5942.

Snider WD (1994) Functions of the neurotrophins during nervous system development: what the knockouts are teaching us. Cell 77:627-638.

Snider WD, McMahon SB (1998) Tackling pain at the source: new ideas about nociceptors. Neuron 20:629-632.

Snider WD, Zhang L, Yusoof S, Gorukanti N, Tsering C (1992) Interactions between dorsal root axons and their target motor neurons in developing mammalian spinal cord. J Neurosci 12:3494-3508.

Standifer KM, Chien CC, Wahlestedt C, Brown GP, Pasternak GW (1994) Selective loss of delta opioid analgesia and binding by antisense oligodeoxynucleotides to a delta opioid receptor. Neuron 12:805-810.

Sugi Y, Sasse J, Barron M, Lough J (1995) Developmental expression of fibroblast growth factor receptor-1 (cek-1; flg) during heart development. Dev Dyn 202:115-125.

Templeton TJ, Hauschka SD (1992) FGF-mediated aspects of skeletal muscle growth and differentiation are controlled by a high affinity receptor, FGFR1. Dev Biol 154:169-181.

Vaccarino FM, Schwartz ML, Raballo R, Nilsen J, Rhee J, Zhou M, Doetschman T, Coffin JD, Wyland JJ, Hung YT (1999) Changes in cerebral cortex size are governed by fibroblast growth factor during embryogenesis. Nat Neurosci [Errata (1999) 2:485, 848] 2:246-253.

Vescovi AL, Reynolds BA, Fraser DD, Weiss S (1993) bFGF regulates the proliferative fate of unipotent (neuronal) and bipotent (neuronal/ astroglial) EGF-generated CNS progenitor cells. Neuron 11:951-966.

Vogel KS (1993) Development of trophic interactions in the vertebrate peripheral nervous system. Mol Neurobiol 7:363-382.

Wetts R, Vaughn JE (1998) Peripheral and central target requirements for survival of embryonic rat dorsal root ganglion neurons in slice cultures. J Neurosci 18:6905-6913.

Wewetzer K, Lausch M, Christ B (1999) Macrowell cultures identify a subpopulation of neonatal rat dorsal root ganglionic neurons displaying nerve growth factor independent survival. Neurosci Lett 276:9-12.

Wheeler EF, Gong H, Grimes R, Benoit D, Vazquez L (1998) p75NTR and Trk receptors are expressed in reciprocal patterns in a wide variety of non-neural tissues during rat embryonic development, indicating independent receptor functions. J Comp Neurol 391:407-428.

White FA, Silos-Santiago I, Molliver DC, Nishimura M, Phillips H, Barbacid M, Snider WD (1996) Synchronous onset of NGF and TrkA survival dependence in developing dorsal root ganglia. J Neurosci 16:4662-4672.

Wilson L, Hand G (1997) The pressor reflex evoked by static contraction: neurochemistry at the site of the first synapse. Brain Res Brain Res Rev 23:169-209.

Wood J, Docherty R (1997) Chemical activators of sensory neurons. Annu Rev Physiol 59:457-482.

Wood J, Perl E (1999) Pain. Curr Opin Genet Dev 9:328-332.

Wright DE, Zhou L, Kucera J, Snider WD (1997) Introduction of a neurotrophin-3 transgene into muscle selectively rescues proprioceptive neurons in mice lacking endogenous neurotrophin-3. Neuron 19:503-517.

Yao R, Cooper GM (1995) Requirement for phosphatidylinositol-3 kinase in the prevention of apoptosis by nerve growth factor. Science 267:2003-2006.

Zheng F, Lawson SN (1994) Immunocytochemical properties of rat renal afferent neurons in dorsal root ganglia: a quantitative study. Neuroscience 63:295-306.

Zhou XF, Rush R (1995a) Sympathetic neurons in neonatal rats require endogenous neurotrophin-3 for survival. J Neurosci 15:6521-6530.

Zhou XF, Rush RA (1995b) Peripheral projections of rat primary sensory neurons immunoreactive for neurotrophin 3. J Comp Neurol 363:69-77. 